\title{
Nav1.6 Sodium Channels Are Critical to Pacemaking and Fast Spiking in Globus Pallidus Neurons
}

\author{
Jeff N. Mercer, C. Savio Chan, Tatiana Tkatch, Joshua Held, and D. James Surmeier \\ Department of Physiology, Feinberg School of Medicine, Northwestern University, Chicago, Illinois 60611
}

\begin{abstract}
Neurons in the external segment of the globus pallidus (GPe) are autonomous pacemakers that are capable of sustained fast spiking. The cellular and molecular determinants of pacemaking and fast spiking in GPe neurons are not fully understood, but voltage-dependent $\mathrm{Na}^{+}$ channels must play an important role. Electrophysiological studies of these neurons revealed that macroscopic activation and inactivation kinetics of their $\mathrm{Na}^{+}$channels were similar to those found in neurons lacking either autonomous activity or the capacity for fast spiking. What was distinctive about $\mathrm{GPe} \mathrm{Na}{ }^{+}$channels was a prominent resurgent gating mode. This mode was significantly reduced in GPe neurons lacking functional Nav1.6 channels. In these Nav1.6 null neurons, pacemaking and the capacity for fast spiking were impaired, as was the ability to follow stimulation frequencies used to treat Parkinson's disease (PD). Simulations incorporating $\mathrm{Na}^{+}$ channel models with and without prominent resurgent gating suggested that resurgence was critical to fast spiking but not to pacemaking, which appeared to be dependent on the positioning of $\mathrm{Na}^{+}$channels in spike-initiating regions of the cell. These studies not only shed new light on the mechanisms underlying spiking in GPe neurons but also suggest that electrical stimulation therapies in PD are unlikely to functionally inactivate neurons possessing Nav1.6 $\mathrm{Na}^{+}$channels with prominent resurgent gating.
\end{abstract}

Key words: patch clamp; Parkinson's disease; deep brain stimulation; scRT-PCR; burst firing; Nav1.6; Nav1.1; resurgent; basal ganglia; NEURON; med $^{T G}$

\section{Introduction}

The external segment of the globus pallidus (GPe) is a key component of the basal ganglia circuitry controlling movement (Albin et al., 1989). In vivo, GABAergic GPe neurons normally exhibit sustained fast spiking that is interrupted by pauses that are associated with movement (Wichmann and DeLong, 1999). In Parkinson's disease (PD), the activity of many GPe neurons changes and episodes of rhythmic, fast spiking become common (Filion and Tremblay, 1991; Wichmann and DeLong, 1999; Raz et al., 2000, 2001). Similar patterns of activity emerge in the synaptically coupled internal segment of the globus pallidus and the subthalamic nucleus (STN) (Bevan et al., 2002). This pathological pattern of spiking is thought to be responsible for PD motor symptoms because they are alleviated by lesioning or deep brain stimulation (DBS) of these nuclei (Bergman et al., 1990; Benabid et al., 2002).

The intrinsic properties of GPe neurons that control spiking in health and disease are not well understood. What is known is that these neurons are unusual in that they are both autonomous pacemakers and capable of fast spiking (Kita and Kitai, 1991; Nambu and Llinas, 1994; Chan et al., 2004; Surmeier et al., 2005). In other cell types, voltage-dependent $\mathrm{Na}^{+}$channels are primary

Received Dec. 6, 2006; revised 0ct. 2, 2007; accepted Oct. 2, 2007

This work was supported by National Institutes of Health Grants NS047085 and NS41234 (D.J.S.). We thank Sasha Ulrich and Karen Saporito for their help with PCR and animal husbandry.

Correspondence should be addressed to D. James Surmeier, Department of Physiology, Feinberg School of Medicine, Northwestern University, 303 East Chicago Avenue, Chicago, IL 60611. E-mail: j-surmeier@northwestern.edu. D0I:10.1523/JNEUROSCI.3430-07.2007

Copyright $\odot 2007$ Society for Neuroscience 0270-6474/07/2713552-15\$15.00/0 determinants of both behaviors. In cerebellar Purkinje neurons, for example, $\mathrm{Na}^{+}$channels with a pore-forming Nav1.6 $\alpha$ subunit reopen during the falling phase of the spike, giving rise to a resurgent current that promotes fast spiking (Raman and Bean, 1997; Khaliq et al., 2003). These channels have also been implicated in the maintenance of autonomous pacemaking in these cells (Khaliq et al., 2003; Levin et al., 2006). In contrast, loss of functional Nav1.6 channels in the STN has little effect on either pacemaking or fast spiking (Do and Bean, 2003). Although voltage-dependent $\mathrm{Na}^{+}$channels are critical to autonomous pacemaking in GPe neurons (Kita and Kitai, 1991; Nambu and Llinas, 1994; Chan et al., 2004), it is not known to what extent different $\mathrm{Na}^{+}$channels or their gating control pacemaking or fast spiking.

In addition to determining naturally occurring spiking patterns, $\mathrm{Na}^{+}$channels also are undoubtedly critical to how GPe neurons respond to DBS. DBS was originally thought to functionally inactivate neurons by producing depolarization block of $\mathrm{Na}^{+}$channels (Benabid et al., 1998). Although more recent work has questioned this inference (Benabid et al., 2002; Lozano et al., 2002; Vitek et al., 2004), the prevailing view remains that functional activity of targeted structures is suppressed by DBS. Direct electrophysiological examination of changes produced by highfrequency stimulation (HFS) revealed a substantial reduction in $\mathrm{Na}^{+}$channel availability in acutely isolated STN neurons (Do and Bean, 2003). However, it is not clear whether this result can be generalized to other fast-spiking basal ganglia neurons such as GPe neurons.

The studies reported here used electrophysiological, computational, and molecular approaches to characterize $\mathrm{Na}^{+}$channels 
in GPe neurons that underlie fast spiking and pacemaking, as well as the response to DBS. Our results suggest that, although GPe neurons express several types of $\mathrm{Na}^{+}$channels, it is Nav1.6 channels with resurgent gating that are critical to fast spiking, as in Purkinje neurons. However, it appears that the location and density of these channels (not their resurgence) is what underlies their role in pacemaking.

\section{Materials and Methods}

Animals. Male C57BL/6 mice [postnatal day 17 (P17) to P22; Charles River, Wilmington, MA] were used in the present study. C57BL/6 mice (P16-P21) with the med $^{T G}$ mutation (Nav1.6 null) were obtained from Dr. Miriam Meisler Laboratory at the University of Michigan (Kohrman et al., 1995). Data from congenic wild-type littermates and C57BL/6 mice were indistinguishable and were thus pooled.

The handling of mice and all procedures performed on them were approved by the Animal Care and Use Committee of Northwestern University and were in accordance with the National Institutes of Health Guide to the Care and Use of Laboratory Animals and Society for Neuroscience guidelines. All efforts were made to minimize the number of animals used and the suffering of killed animals.

Tissue preparation. Animals were anesthetized with isoflurane and decapitated. Brains were removed rapidly and placed immediately in icecold artificial CSF (ACSF) [in mM: $125 \mathrm{NaCl}, 2.5 \mathrm{KCl}, 1 \mathrm{MgCl}_{2}, 2 \mathrm{CaCl}_{2}$, $1.25 \mathrm{NaH}_{2} \mathrm{PO}_{4}, 13$ glucose, and $25 \mathrm{NaHCO}_{3}$, bubbled continuously with carbogen $\left(95 \% \mathrm{O}_{2}\right.$ and $\left.5 \% \mathrm{CO}_{2}\right)$ (slice experiments)] or ice-cold sucrose solution [in mM: 250 sucrose, 11 glucose, 15 HEPES, $4 \mathrm{MgSO}_{4}, 1$ $\mathrm{NaH}_{2} \mathrm{PO}_{4}, 2.5 \mathrm{KCl}, 1$ kynurenic acid, and $0.1 \mathrm{~N}$-nitro-L-arginine, and 0.005 glutathione, $\mathrm{pH} 7.4$ (300-305 mOsm/liter bubbled continuously with oxygen (acute experiments)]. Thin coronal slices $(250-300 \mu \mathrm{m})$ containing globus pallidus (the external globus pallidus in primates is equivalent to the globus pallidus in rodents, which was studied in this project and will be referred to as the GPe; the primate internal globus pallidus is equivalent to the rodent entopeduncular nucleus) were made using a vibrating microtome (VT1000s; Leica via Leitz, Nussloch, Germany) and incubated for $0.5-4 \mathrm{~h}$ in ACSF (slice experiments) or sodium bicarbonate-buffered Earle's balanced salt solution (EBSS) bubbled with carbogen (acute experiments). EBSS also contained the following (in mм): 23 glucose, 1 kynurenic acid, $0.1 \mathrm{~N}$-nitro-L-arginine, and 0.005 glutathione.

For voltage-clamp experiments with acutely isolated neurons, individual slices were transferred to a low- $\mathrm{Ca}^{2+}$ buffer [in mM: $140 \mathrm{Na}$ isethionate, 23 glucose, $15 \mathrm{HEPES}, 2 \mathrm{KCl}, 4 \mathrm{MgCl}_{2}, 0.2 \mathrm{CaCl}_{2}, 1$ kynurenic acid, $0.1 \mathrm{~N}$-nitro-L-arginine, and 0.005 glutathione, $\mathrm{pH} 7.4$ (300-305 mOsm/ liter)], and the GPe was dissected and incubated at $30^{\circ} \mathrm{C}$ for $25 \mathrm{~min}$ in oxygenated HBSS [in mm: $11 \mathrm{HEPES}, 4 \mathrm{MgCl}_{2}, 1 \mathrm{CaCl}_{2}, 1$ pyruvic acid, 1 kynurenic acid, $0.1 \mathrm{~N}$-nitro-L-arginine, 0.005 glutathione, and $1 \mathrm{mg} / \mathrm{ml}$ protease XIV, pH 7.4 (300-305 mOsm/liter, bubbled with $\left.\mathrm{O}_{2}\right)$ ]. After enzyme incubation, the tissue was transferred to the low-Ca ${ }^{2+}$ HEPESbuffered saline, rinsed, and mechanically dissociated using fire-polished Pasteur pipettes. The resulting cell suspension was plated onto a $35 \mathrm{~mm}$ Petri dish mounted onto an inverted microscope. During the course of the experiment, nonrecorded cells were constantly perfused with a background solution containing the following (in $\mathrm{mm}$ ): $140 \mathrm{NaCl}, 23$ glucose, 15 HEPES, $2 \mathrm{KCl}, 2 \mathrm{MgCl}_{2}$, and $1 \mathrm{CaCl}_{2}$, pH 7.4 (300-305 mOsm/liter).

Whole-cell and cell-attached recording in slices. Slices were transferred to a small volume $(<0.5 \mathrm{ml})$ recording chamber that was mounted on a fixed-stage, upright microscope (BX51; Olympus Optical, Melville, NY) equipped with infrared differential interference contrast (IR-DIC) [0.9 numerical aperture (NA)] with de Sénarmont compensation (Olympus Optical). Experiments were performed at room temperature $\left(22^{\circ} \mathrm{C}\right)$. The recording chamber was superfused with carbogen-saturated ACSF with a flow rate of $2-3 \mathrm{ml} / \mathrm{min}$. Neuronal somata and proximal dendrites were visualized by video microscopy at high magnification $(60 \times, 0.9 \mathrm{NA}$ water immersion objective; Olympus Optical) with a back-thinned, frametransfer cooled CCD camera (Micromax EBFT512; Roper Scientific, Trenton, NJ) aided by a contrast enhancement system (Argus-20; Hamamatsu Photonics, Bridgewater, NJ).
Conventional tight-seal (>3 G $\Omega$ ) whole-cell patch-clamp and cellattached recordings were made on visually identified, GPe neurons based on size and somatodendritic morphology. Only neurons in the rostral to midlevel GPe were studied (Shammah-Lagnado et al., 1996). GPe neurons were further identified by their physiological features (Chan et al., $2004)$, including resting level of discharge $(\sim 12 \mathrm{~Hz}$ during cell-attached recording) and prominent voltage sag during hyperpolarizing current injection. Neurons that were included in the sample had (1) basal discharge rate $>8 \mathrm{~Hz}$, (2) evidence of HCN currents with a $-100 \mathrm{pA}, 500 \mathrm{~ms}$ current step, and (3) a spike width at spike threshold that did not exceed $1.5 \mathrm{~ms}$.

Patch electrodes (1.5 mm outer diameter) were fabricated from filamented, thick-walled borosilicate glass (Sutter Instruments, Novato, CA) pulled on a Flaming-Brown puller (P-97; Sutter Instruments) and fire polished immediately before use. Pipette resistance was typically 3-6 $\mathrm{M} \Omega$ when filled with recording solution. The recording internal solution consisted of the following (in $\mathrm{mm}$ ): $140 \mathrm{KMeSO}_{4}, 5 \mathrm{KCl}, 10 \mathrm{Na}$ phosphocreatine, 0.025-0.05 EGTA, 2.0 Mg-ATP, $0.4 \mathrm{Na}_{3}$-GTP, and 10 HEPES, pH 7.25-7.30 (280 mOsm). The liquid junction potential between our internal solution and ACSF was estimated to be $\sim 7 \mathrm{mV}$; this was estimated by measuring the potential change produced by moving the tip of an electrode filled with normal internal solution from an identical solution (in which there should be no liquid junction potential) to the normal external solution. The $7 \mathrm{mV}$ difference was subtracted from all records. Somatic whole-cell patch-clamp recordings were obtained via a MultiClamp 700B amplifier (Molecular Devices, Union City, CA) interfaced to a Pentium-based personal computer running pClamp9 (Molecular Devices). The signal was filtered at $1-4 \mathrm{kHz}$ and digitized at 5-20 $\mathrm{kHz}$ with a Digidata 1322A (Molecular Devices). For current-clamp recordings, the amplifier bridge circuit was adjusted to compensate for electrode resistance and monitored. Electrode capacitance was also compensated. If series resistance increased $>20 \%$ during recording, the data were discarded.

Whole-cell recording in the acutely dissociated preparation. Voltageclamp recordings were performed using electrodes pulled from Corning (Corning, NY) 7052 glass, coated with R-6101 (Corning) and fire polished immediately before use. Electrodes were typically $2-3 \mathrm{M} \Omega$ in the bath. Recordings were obtained via an Axopatch 200B amplifier (Molecular Devices) interfaced to a Macintosh computer running Pulse software (HEKA Elektronik, Lambrecht, Germany) through an ITC-16 (InstruTech, Port Washington, NY). After the gigaohm seal was formed and the cell membrane was ruptured, series resistance was compensated (75$80 \%)$ and frequently monitored. The intracellular recording solution contained the following (in $\mathrm{mM}$ ): $60 \mathrm{~mm} \mathrm{~N}$-methyl-D-glutamine, 20 HEPES, $50 \mathrm{Cs}_{2} \mathrm{SO}_{4}, 2 \mathrm{MgCl}_{2}, 0.5 \mathrm{Na}_{2} \mathrm{SO}_{4}, 22$ phosphocreatine, $3 \mathrm{~mm}$ Mg-ATP, $0.7 \mathrm{Na}_{2}$-GTP, and 0.1 leupeptin, pH 7.25 (with $\mathrm{H}_{2} \mathrm{SO}_{4}$, 265$270 \mathrm{mOsm} /$ liter). During recording, cells were bathed in extracellular solutions applied via a gravity-fed capillary perfusion array positioned several hundred micrometers away from the cell under study. Bathing solutions were changed by adjusting the position of the array using a direct current actuator (Newport, Irving, CA). Solution changes were complete within $<1$ s. For recording transient $\mathrm{Na}^{+}$currents, the external solution contained the following (in $\mathrm{mM}$ ): $10 \mathrm{NaCl}, 110$ tetraethylammonium (TEA) chloride, $10 \mathrm{HEPES}, 10 \mathrm{CsCl}, 0.3 \mathrm{CdCl}_{2}, 1 \mathrm{MgCl}_{2}$, and 2 $\mathrm{BaCl}_{2}$, pH 7.4 (300-305 mOsm/liter). For recording subthreshold $\mathrm{Na}^{+}$ currents, the external solution contained the following (in $\mathrm{mM}$ ): 115 $\mathrm{NaCl}$, 45 TEA-Cl, 10 HEPES, $0.3 \mathrm{CdCl}_{2}, 1 \mathrm{MgCl}_{2}$, and $2 \mathrm{BaCl}_{2}, \mathrm{pH} 7.4$ (300-305 mOsm/liter). In all of our voltage-clamp studies, neurons were initially patched in the low $\mathrm{Na}^{+}$external solution. The liquid junction potential between our internal solution and the reduced $\mathrm{Na}^{+}$external solution was estimated by the approach described above; the potential was consistently $<4 \mathrm{mV}$ and was not corrected for. Protocols were repeated in external solution plus $300 \mathrm{~nm}$ tetrodotoxin (TTX), and these recordings were subtracted from the control records to isolate TTXsensitive sodium current. Unless noted otherwise, all chemicals were obtained from Sigma (St. Louis, MO). All recordings were performed at room temperature $\left(22^{\circ} \mathrm{C}\right)$.

In the vast majority of neurons ( $\sim 90 \%)$, peak currents were $<1 \mathrm{nA}$ with $10 \mathrm{mM} \mathrm{Na}^{+}$external solutions. In these cells, the voltage error 
introduced by uncompensated series resistance was estimated to be $<1$ $\mathrm{mV}(75 \%$ compensation of $3 \mathrm{M} \Omega$ yields $750 \mathrm{~K} \Omega$ residual series resistance $\times 1 \mathrm{nA}=0.75 \mathrm{mV}$ ). Cells with $>2 \mathrm{nA}$ peak currents (yielding $\sim 2$ $\mathrm{mV}$ error) were discarded.

To ensure adequate voltage control, several additional steps (beyond recording in reduced $\mathrm{Na}^{+}$solutions) were taken. Only cells with relatively short $(25-50 \mu \mathrm{m})$ processes were selected for recording; after entering whole-cell mode, often the processes retracted, making cells nearly spherical. In each cell, current activation plots were generated, and any evidence of loss of voltage control (discontinuities in the current-voltage relationship that would yield slope factors $<5 \mathrm{mV}$ ) resulted in the cell being discarded. Also, variation in the activation kinetics of test pulse currents evoked in inactivation protocols was taken for evidence of bad space clamp. In the ramp experiments in which external $\mathrm{Na}^{+}$was near physiological levels, discontinuities in the rising phase of the currents was taken as evidence as bad control in the worst case, and this was manifested as spiking; peak currents in these situations were invariably small $(<300 \mathrm{pA})$, making series resistance errors small. In some cases, control was reestablished by reducing the $\mathrm{Na}^{+}$current driving force and the experiments were repeated.

Data analysis. Data were plotted and analyzed with IgorPro (WaveMetrics, Lake Oswego, OR). Transient $\mathrm{Na}^{+}$currents evoked by depolarizing steps were fit with a modified Hodgkin-Huxley $(\mathrm{HH})$ formalism of the form $g=g_{\max } m^{3}(V, t) h(V, t)\left(V-V_{\text {rev }}\right)$, where $g$ is the conductance, $g_{\max }$ is the maximal conductance, $V$ is transmembrane voltage, $t$ is time, $V_{\text {rev }}$ is the $\mathrm{Na}^{+}$reversal potential, $m(V, t)=\alpha\left(1-\exp \left(-t / \tau_{\mathrm{m}}\right)\right), h(V, t)=$ $\beta\left(\exp \left(-t / \tau_{\mathrm{h} 1}\right)\right)+(1-\beta-\gamma)\left(\exp \left(-\mathrm{t} / \tau_{\mathrm{h} 2}\right)\right)+\gamma$, where $\alpha$ is a scalar, $0<\beta<1$ (the component of inactivation that decays with a $\tau_{\mathrm{h} 1}$ time constant), and $\gamma$ is a scalar representing the component of the current that is persistent (typically $0.01-0.05$ ), $\tau_{\mathrm{m}}$ is the activation time constant, and $\tau_{\mathrm{h} 1}$ and $\tau_{\mathrm{h} 2}$ are the fast and slow inactivation time constants. The development of inactivation between -60 and $-40 \mathrm{mV}$ was estimated by stepping into this voltage range for a variable period before delivering a test step to assay for deinactivated channels. Inactivation kinetics were determined by fitting measurements of peak current as a function of prepulse duration. Deactivation kinetics were estimated by briefly depolarizing the membrane to open channels and then repolarizing to hyperpolarized membrane potentials. These tail currents were fit with simple monoexponential or biexponential functions. Nominally steady-state conductance-voltage and inactivation-voltage curves were fit with a Boltzmann function of the following form: $g(V)=1 /\left(1+\exp \left(\left(V-V_{1 / 2}\right) /\right.\right.$ $\left.\left.V_{c}\right)\right)^{C}$, where $V_{1 / 2}$ is the half-activation or inactivation voltage, and $V c$ is the slope factor. Activation data were fit with a third-order $(c=3)$ and inactivation was fit with a first-order $(c=1)$ Boltzmann function. Window current estimates and fits of persistent currents were generated assuming that the current was given by $\zeta\left(\mathrm{m}^{3}(V, \infty)(h(V, \infty)+\gamma)\right)(V-$ $V_{\text {rev }}$ ). Driving force was estimated from the Nernst equation (as described above) or from the Goldman-Hodgkin-Katz equation (Hille, 2001); there were only small differences in the estimates of conductance or permeability (respectively) derived from these choices in driving force estimates with the ionic concentrations used. Activation and deactivation time constants were plotted as a function of voltage and fit with an equation of the following form: $c 1+c 2 /(\alpha 1 \exp (-(V-\alpha 2) / \alpha 3)+\beta$ $1 \exp ((V+\beta 2) / \beta 3))$, where $V$ is transmembrane voltage and $\alpha 1-\alpha 3$, $\beta 1-\beta 3$, and $c 1-c 2$ are fitted constants. This equation is derived from the Hodgkin-Huxley formalism and assumes a single voltage-dependent state transition. Slow inactivation-voltage curves were fit with a modified Boltzmann equation of the following form: $I / I_{\max }=\left(1-I_{\text {resid }}\right) /((1+$ $\left.\exp \left(-\left(V-V_{1 / 2}\right) / V_{c}\right)\right)+I_{\text {resid, }}$, where $I_{\text {resid }}$ is the residual (noninactivating) fraction of the current, and $V_{c}$ is the slope factor. Time constants for the entry into the slow inactivated state were reasonably fit with a single-exponential function; exit from the slow inactivated state required a double-exponential fit.

Statistical analyses were performed using Systat (SPSS, Chicago, IL). Sample statistics are given as mean \pm SEM or median if accompanied with a nonparametric box plot of data spread. In data presented as box plots, the central line represents the median, the edges of the box represents interquartiles, and the "whisker lines" show the extent of the overall distribution, excluding outliers (points $>1.5 \times$ interquartile range).
Tissue and single-cell reverse transcription-PCR analysis. Acutely isolated neurons were aspirated into sterilized glass pipettes containing nominally RNase-free patch solution or diethylpyrocarbonate-treated water and $0.8 \mathrm{U} / \mu \mathrm{l}$ SUPERase-In (Ambion, Austin, TX). Sterile gloves were worn during the procedure to minimize RNase contamination. After aspiration, the contents of the pipette were ejected into $0.6 \mathrm{ml}$ presiliconized tubes (Midwest Scientific, Valley Park, MO) containing a reverse transcription (RT) mix. This mix contained $0.7 \mu$ l of Superase-IN $(20 \mathrm{U} / \mu \mathrm{l}), 1.9 \mu \mathrm{l}$ of diethylpyrocarbonate-treated water, $1 \mu \mathrm{l}$ of dNTPs (10 mM), $0.7 \mu \mathrm{l}$ of BSA $(143 \mu \mathrm{g} / \mu \mathrm{l})$, and $0.7 \mu \mathrm{l}$ of oligo-dT $(0.5 \mu \mathrm{g} / \mu \mathrm{l})$. Together with cell contents, the mixture was heated to $65^{\circ} \mathrm{C}$ for $5 \mathrm{~min}$ to linearize mRNA and then placed on ice for at least $1 \mathrm{~min}$. Single-strand cDNA was synthesized from the cellular mRNA by adding $2 \mu \mathrm{l}$ of $10 \times$ PCR buffer, $4 \mu \mathrm{l}$ of $\mathrm{MgCl}_{2}$ ( $\left.25 \mathrm{~mm}\right), 2 \mu \mathrm{l}$ of DTT $(0.1 \mathrm{M}), 1 \mu \mathrm{l}$ of RNase out $(40 \mathrm{U} / \mu \mathrm{l})$, and $6 \mu \mathrm{l}$ of diethylpyrocarbonate-treated water. This mixture was then incubated at $42^{\circ} \mathrm{C}$ for $2 \mathrm{~min}$. After the initial incubation, 0.7 $\mu \mathrm{l}$ of Superscript II $(50 \mathrm{U} / \mu \mathrm{l})$ was added, and the mixture was kept at $42^{\circ} \mathrm{C}$ for an additional $50 \mathrm{~min}$. The reaction was terminated by heating to $70^{\circ} \mathrm{C}$ for $15 \mathrm{~min}$. The RNA strand in the RNA-DNA hybrid was then removed by adding $0.5 \mu \mathrm{l}$ of RNase $\mathrm{H}(2 \mathrm{U} / \mu \mathrm{l})$ and incubating at $37^{\circ} \mathrm{C}$ for $20 \mathrm{~min}$. All reagents except Superase-IN (Ambion) were obtained from Invitrogen (Gaithersburg, MD). Single-cell (sc) cDNA was amplified using a conventional PCR approach with a programmable thermal cycler (MJ Research, Watertown, MA). PCR primers were developed from GenBank sequences with commercially available OLIGO 6.7.1 software (National Biosciences, Plymouth, MN). Primers and reaction protocols for choline acetyltransferase (ChAT), glutamic acid decarboxylase (GAD67), parvalbumin (PV), enkephalin (ENK), Nav $\beta 1, N a v \beta 2$, and Nav 33 , and Nav1.1, Nav1.2, and Nav1.6 channels have been described previously (Song et al., 1998; Tkatch et al., 1998; Maurice et al., 2004; Surmeier et al., 2005). The primers for $\mathrm{Na} \beta 4$ cDNA (GenBank accession number BK001031) were GGATCGTGAAGAACGATAAGT (position 245) and AGCCAGGATGATGAGAGTCACCG (position 482). The predicted product length was 260. After amplification, PCR products were labeled by ethidium bromide and separated by electrophoresis on agarose gels. Amplicons were of the expected size and sequence. RT-PCR was performed using procedures designed to minimize the chance of cross-contamination. Negative controls for contamination from extraneous DNA were run for every batch of neurons. Contamination from extraneous sources was checked by eliminating the cellular template for one reverse transcript reaction. The controls were consistently negative in these experiments.

NEURON simulations. Experimentally recorded currents were modeled with NEURON, version 5.9 (Hines and Carnevale, 1997, 2001). All experimental data on TTX-sensitive sodium currents were obtained in this study and incorporated into a kinetic scheme based on previously derived models (Kuo and Bean, 1994; Carr et al., 2003). The factor $a$ from previous models was replaced with $m$ and $n$, where $m=(($ Oon/Ooff $) /$ $($ Con/Coff $))^{\wedge}(1 / 2)$ (preserving microscopic reversibility), and $n=2$. Furthermore, the rates Oon, Ooff, $\zeta, \alpha S_{X}$ (where $X$ is $o, b$, or $i$ depending on the states between which the transition occurs) were made voltage dependent. The rates were calculated by Oon $=\operatorname{Oon} 0 \times \exp ((v-$ hOon $) /$ cOon $),$ Ooff $=$ Ooffo $\times \exp ((v-$ hOoff $) / c O o f f), \zeta=$ blo $\times$ $\exp (-(v-b v h) / b$ slope $)$, and $\alpha S_{X}=S_{X} R \times \exp \left(\left(v-S_{X} H\right) / S_{X} C\right)$. The single slow inactivated states from Carr et al. (2003) were replaced with 10 slow inactivated states. The values of all rate constants have been altered to more accurately fit the adjustments made to the model scheme. NEURON mod files containing these descriptions are available on request. The Nav1.6 channel model (modNav1.6) was modified from the model Nav1.1/1.2 channels (modNav1.1) by increasing $b 10$ from 0.08 to 0.15 and decreasing Ooffo from 3 to 0.77 .

The model GPe neuron was constructed of a cylindrical soma (length $\times$ diameter, $25 \times 25 \mu \mathrm{m}$ ), a cylindrical hillock (length $\times$ diameter, $15 \times 3.2 \mu \mathrm{m}$ ), an axon initial segment (AIS) (length $\times$ diameter, $30 \times 1.4 \mu \mathrm{m}$ ), a cylindrical axon consisting of an unmyelinated section (length $\times$ diameter, $50 \times 1 \mu \mathrm{m}$ ), followed by a sequence of five myelinated sections (length $\times$ diameter, $100 \times 1 \mu \mathrm{m}$ ) separated by four unmyelinated nodes (length $\times$ diameter, $1 \times 1 \mu \mathrm{m}$ ) and four cylindrical dendrites (length $\times$ diameter, $800 \times 1 \mu \mathrm{m}$ ). Axial resistivity was $150 \Omega \mathrm{cm}$. 
A coronal slice

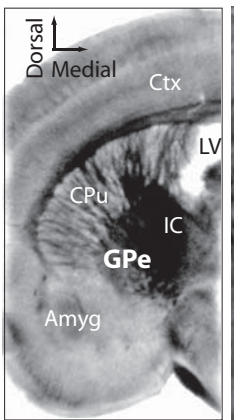

C

control
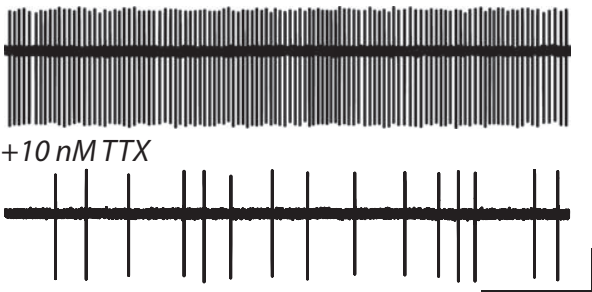

D control

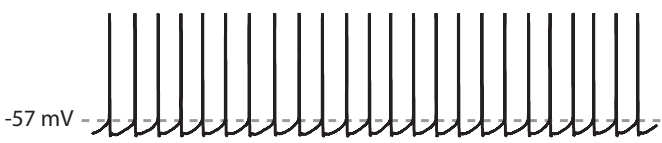

+30 nM TTX
+10 nM TTX
IR-DIC
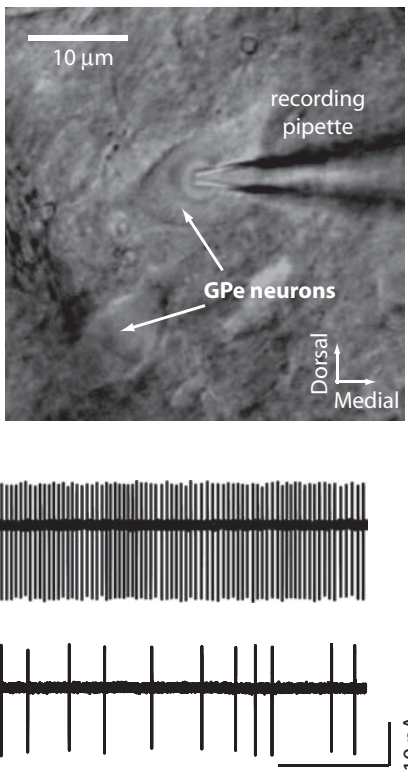

$2 \mathrm{sec}$

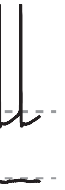

B

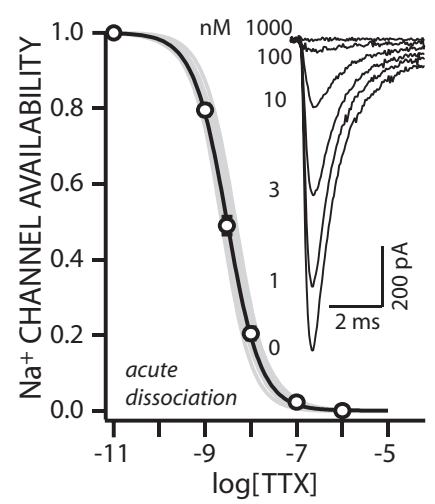

E autonomous firing rate

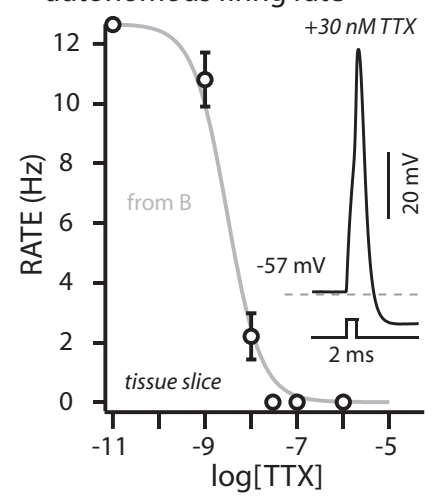

Figure 1. Firing rate of GPe neurons is sensitive to $\mathrm{Na}^{+}$channel availability. $A$, Left, Light micrograph of a coronal mouse slice showing the location of the GPe and adjacent structures. GPe is sandwiched between the curve of the lateral caudate-putamen $(\mathrm{CPu})$ and the medial internal capsule (IC). The high density of myelinated fibers gives the nucleus a very distinctive, opaque appearance (Amyg, amygdale; LV, lateral ventricle; (tx, cortex). Right, IR-DIC micrograph showing GPe neurons from a tissue slice. $B$, Dose-response curve for TTX in the dissociated, voltage-clamped preparation. $\mathrm{Na}^{+}$current was measured by $5 \mathrm{~ms}$ voltage steps to $-20 \mathrm{mV}$ from $-80 \mathrm{mV}$ (inset). The smooth curve represents fitting of the data with a Hill-Langmuir equation, yielding an $\mathrm{IC}_{50}$ of $3.1 \pm 0.2 \mathrm{~nm}(n=6)$. C, Extracellular unit activity of a visually identified GPe neuron measured with non-invasive, tight-seal cell-attached patch recording in standard ACSF (top) and $10 \mathrm{~nm} \mathrm{TTX} \mathrm{(bottom).} \mathrm{D,} \mathrm{Under} \mathrm{whole-cell} \mathrm{recording,} 30 \mathrm{~nm}$ TTX blocks spontaneous activity and subthreshold oscillatory activity in a GPe neuron. $E$, The basal firing rate in the presence of TTX is reasonably predicted by $\mathrm{Na}^{+}$channel availability $(n=6)$. Inset, An action potential could still be elicited in $30 \mathrm{~nm} \mathrm{TTX}$, with a $2 \mathrm{ms,}$ $500 \mathrm{pA}$ depolarizing current injection.

Membrane capacitance was $0.75 \mu \mathrm{F} / \mathrm{cm}^{2}$ for myelinated compartments and $0.04 \mu \mathrm{F} / \mathrm{cm}^{2}$ for unmyelinated compartments. For wild-type simulations, modNav1.1 was inserted into the soma and hillock at a density $\left(\mathrm{S} / \mathrm{cm}^{2}\right)$ of 0.2 and 0.1 , respectively; a gradient of modNav1.1 channels was established from the soma $\left(0.0 .08 \mathrm{~S} / \mathrm{cm}^{2}\right)$ to the end of the dendrites $\left(0.008 \mathrm{~S} / \mathrm{cm}^{2}\right)$; modNav1.1 channels were omitted from the rest of the model. modNav1.6 channels were inserted into the AIS $\left(2 \mathrm{~S} / \mathrm{cm}^{2}\right)$, nodes $\left(0.1 \mathrm{~S} / \mathrm{cm}^{2}\right)$, soma $\left(0.05 \mathrm{~S} / \mathrm{cm}^{2}\right)$, and the dendrites (a gradient from 0.02 $\mathrm{S} / \mathrm{cm}^{2}$ near the soma to $0.002 \mathrm{~S} / \mathrm{cm}^{2}$ at the distal end) but omitted from the rest of the model. This sodium channel distribution resembled that used in previous studies (McCormick et al., 2007; Meeks and Mennerick, 2007); spikes originated in the AIS and propagated toward the soma and down the axon. Channel densities were chosen to give an autonomous spiking rate of $\sim 12 \mathrm{~Hz}$. The anatomical parameters were similar to those of GPe neurons but not exact; the general behavior of the model was insensitive to small perturbations in the choice of parameters. For Nav1.6 null simulations, modNav1.6 was eliminated completely. To mimic a situation in which compensation had occurred, modNav1.6 channels were replaced with modNav1.1 channels; at the same density, the autonomous spiking rate was $\sim 10 \mathrm{~Hz}$ and was compensated for by increasing modNav1.1 density by $15 \%$ (resulting in a discharge rate of $13 \mathrm{~Hz}$ ). The response to ramp currents was simulated by placing an electrode on the soma and delivering a $1 \mathrm{~s}$ current ramp from a negative holding potential (as done experimentally).
Also inserted into these compartments were channels known to be important to the spiking of GPe neurons; mod files for HCN1, HCN2, SK, Kv2, Kv3, Kv7 (KCNQ), and Kir2 channels, as well as a $\mathrm{Ca}^{2+}$ buffering system were constrained by experimental data (Baranauskas et al., 1999, 2003; Tkatch et al., 2000; Chan et al., 2004; Shen et al., 2005) or acquired from NEURON database mod files from previous simulations (Migliore et al., 1995; Wang et al., 2002; Khaliq et al., 2003) and incorporated into the appropriate compartments. All simulations were done at $23^{\circ} \mathrm{C}$ and with an $E_{\mathrm{Na}}$ of $50 \mathrm{mV}$. NEURON mod files providing a complete description of the model are available on request and are posted on the NeuronDB web site (http://senselab.med.yale.edu/neurondb).

\section{Results}

Autonomous discharge rate graded with $\mathrm{Na}^{+}$channel availability

In tissue slices held at room temperature $\left(\sim 22^{\circ} \mathrm{C}\right)$, medium-sized, GABAergic GPe projection neurons spike autonomously at just over $10 \mathrm{~Hz}(12.5 \pm 0.3 \mathrm{~Hz} ; n=124)$ in a very regular manner (coefficient of variation, $0.18 \pm 0.01 ; n=124$ ) (Fig. $1 C-E$ ). In contrast, large basal forebrain cholinergic neurons found along the medioventral border of the GPe with the internal capsule were quiescent; these cells were excluded from this study. Although previous work had established the $\mathrm{Na}^{+}$channel dependence of autonomous pacemaking in GPe neurons, the quantitative features of this relationship have not been examined. To fill this gap, the efficacy of $\mathrm{Na}^{+}$channel blocker TTX was determined using acutely isolated GPe neurons in which the $\mathrm{Na}^{+}$ channel currents could be isolated and voltage clamped (Narahashi et al., 1960). Similar to findings in other cell types (Goldin, 2001; Maurice et al., 2004), the TTX dose-response relationship was fit with a single site Hill-Langmuir equation yielding an $\mathrm{IC}_{50}$ of near $3 \mathrm{~nm}$ (Fig. $1 B$ ). Next, to quantify the relationship between $\mathrm{Na}^{+}$channel availability and pacemaking, increasing doses of TTX were applied, and the effect on autonomous discharge of GPe neurons in tissue slices was measured. Unexpectedly, the effect of TTX on $\mathrm{Na}^{+}$channel availability predicted its effect on discharge rate (Fig. $1 B-E$ ). Autonomous pacemaking was more sensitive to $\mathrm{Na}^{+}$channel block than was spiking per se because block of $\sim 95 \%$ of $\mathrm{Na}^{+}$channels eliminated pacemaking without preventing generation of a spike in response to a brief current pulse (Fig. $1 E$, inset).

\section{$\mathrm{Na}^{+}$channels of principal GPe neurons were heterogeneous}

To get a molecular picture of the $\mathrm{Na}^{+}$channels contributing to pacemaking and fast spiking, GPe neurons were acutely isolated from tissue slices and harvested for scRT-PCR profiling. This screen identified two basic cell types: (1) medium-sized neurons that expressed the $67 \mathrm{kDa}$ isoform of GAD67 and either ENK or $\mathrm{PV}$, and (2) large neurons that expressed ChAT but low or undetectable levels of GAD67, ENK, or PV (Fig. 2A). These large cholinergic neurons were excluded from the study. The GABAergic (GAD67-positive) GPe neurons were also profiled for $\mathrm{Na}^{+}$ 
channel subunits and found to express Nav1.1, Nav1.2, and Nav1.6 $\alpha$-subunit mRNAs, in addition to $\mathrm{Na} \beta 1, \mathrm{Na} \beta 2$, $\mathrm{Na} \beta 3$, and $\mathrm{Na} \beta 4$ accessory subunits (supplemental Fig. 1, available at www.jneurosci.org as supplemental material).

\section{$\mathrm{Na}^{+}$channels of GPe neurons had unremarkable fast-gating kinetics}

Acutely isolated, medium-sized GPe neurons were then subjected to biophysical analysis using whole-cell patch-clamp techniques. To maximize the quality of our voltage control, only neurons with relatively short processes were clamped, and the extracellular $\mathrm{Na}^{+}$concentration was lowered. The transient current typically associated with $\mathrm{Na}^{+}$channels was elicited with voltage steps from a holding potential of $-80 \mathrm{mV}$ (Fig. 2B). For the purposes of description, currents were fit with an $\mathrm{HH}$ formalism (Fig. $2 B$, inset). No attempt was made to accurately fit the foot of the rising phase of the currents, because recent work has shown there to be deviations from an $\mathrm{HH}$ formalism (Baranauskas and Martina, 2006); these fits only serve to allow the basic voltage dependence of channel gating to be compared with previous work. Plots of the peak conductance estimates from these fits as a function of step voltage were fit with a thirdorder Boltzmann function. The median half-activation voltage for this third-order function in a sample of GPe neurons was $-38.8 \mathrm{mV}$, and the median slope factor $\left(V_{c}\right)$ was $7.3 \mathrm{mV}(n=19)$. Data are summarized in Figure $2 C$. The median voltage at which the conductance was half-maximum was $-29 \mathrm{mV}$. Deactivation of $\mathrm{Na}^{+}$channels was examined by activating them with a brief step to $-20 \mathrm{mV}$ and then stepping to more hyperpolarized membrane potentials (Fig. $2 D$ ). Currents deactivated monoexponentially at all potentials (at more depolarized potentials, inactivation accounted for the slower component of the biexponential decay seen in the traces). Time constants obtained by fitting these deactivation currents were plotted together with those obtained from the $\mathrm{HH}$ fits described above (Fig. 2E).

To characterize the steady-state voltage dependence of fast inactivation, the membrane potential was stepped to voltages between -110 and $-30 \mathrm{mV}$ for a period sufficient to allow this process to equilibrate $(250 \mathrm{~ms})$, and then a test pulse was given (Fig. 3A). Plots of the peak current evoked by the test pulse as a function of prepulse voltage were accurately described by a first-order Boltzmann function (Fig. 3B). The median half-inactivation voltage was $-53 \mathrm{mV}$, and the slope factor near $5 \mathrm{mV}(n=21)$.

Previous work in the hippocampus suggests that $\mathrm{Na}^{+}$channels in fast-spiking cells have slower inactivation kinetics than do regular spiking neurons (Martina and Jonas, 1997). This was not the case in fast-spiking GPe neurons. Rates of inactivation were determined using three different protocols. At depolarized potentials, the time constant for development of inactivation was determined from the Hodgkin-Huxley fits to the currents evoked in response to step depolarization (Fig. $2 \mathrm{~B}$, inset). Plotting currents evoked by steps to -30 and $0 \mathrm{mV}$ on a log scale revealed two exponentials in the decay of the $\mathrm{Na}^{+}$current (Fig. $3 E$ ). Variance analysis of the $\mathrm{HH}$ fits agreed with this inference, because the mean square variance of the curve fits improved significantly with the addition of a second exponential component but not a third (at $-30 \mathrm{mV}$ ); the relative variance (normalized by the variance of the three-exponential fit) for the first, second and third exponential fits were $3.4,1.02$, and 1 . The development and re- 
A
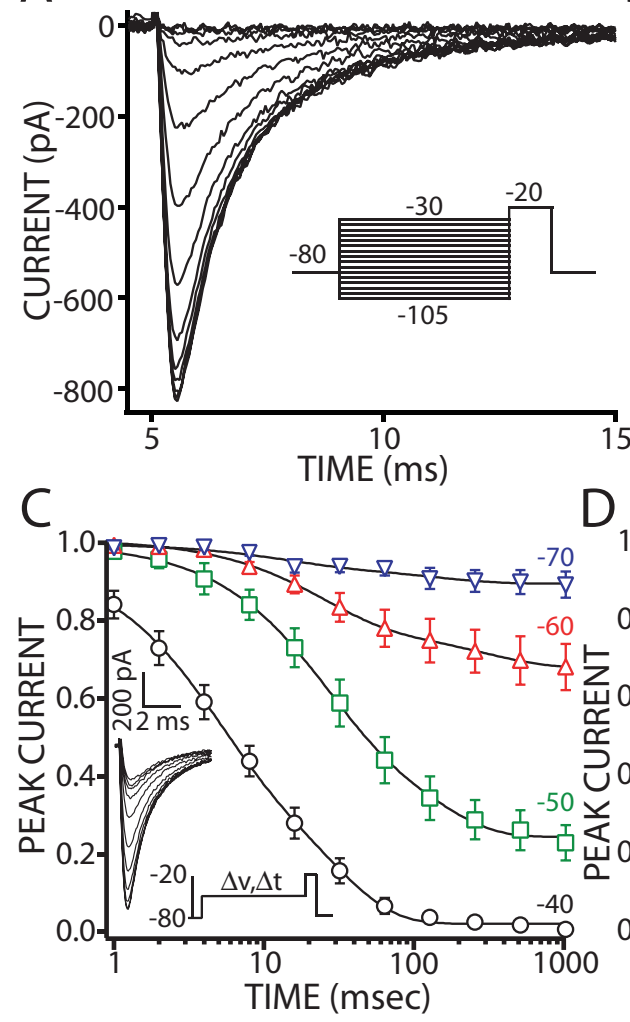

D
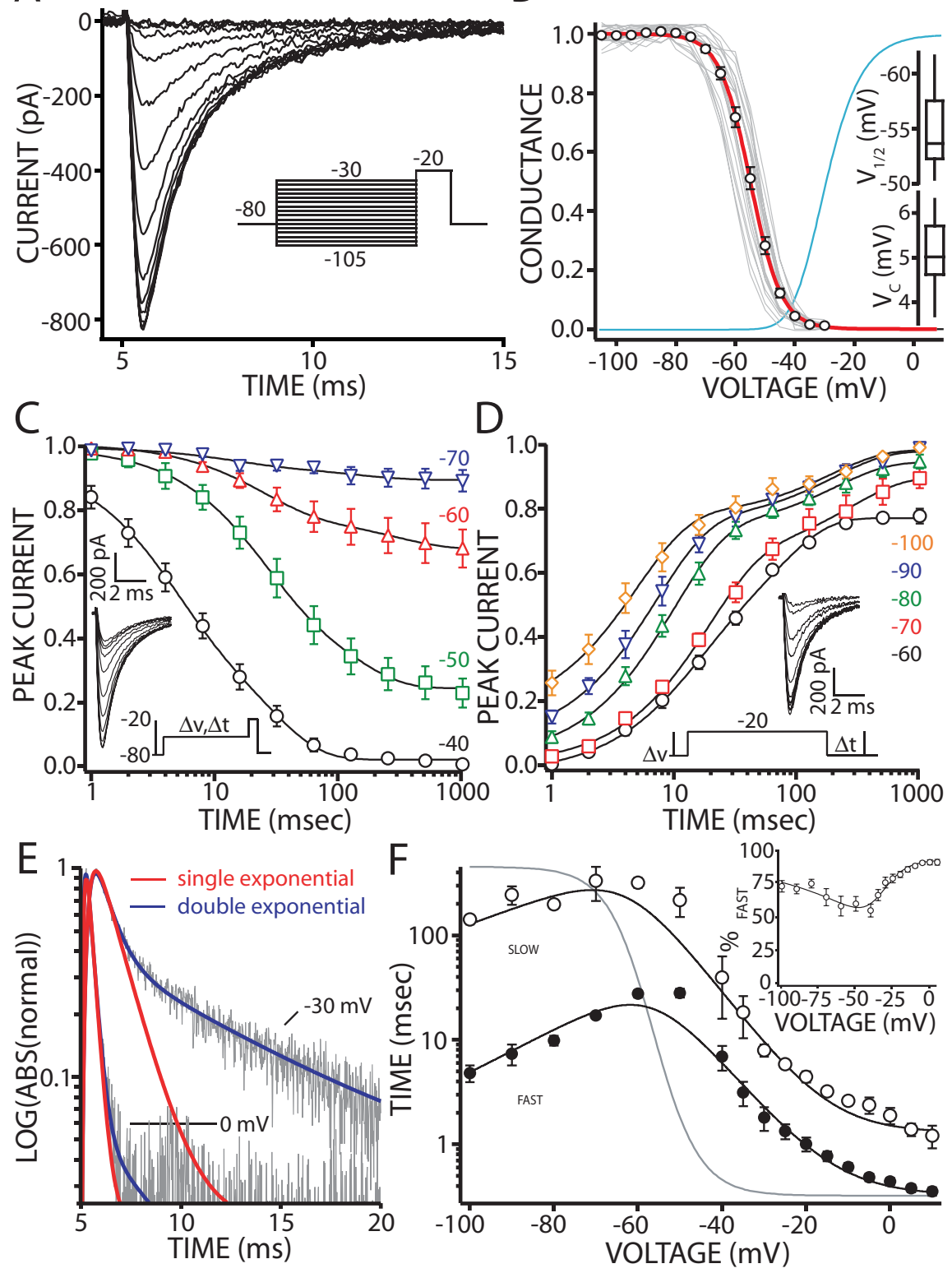

Figure 3. The fast inactivation kinetics of $\mathrm{GPe} \mathrm{Na}^{+}$channels are best described with two time constants. $\boldsymbol{A}$, The voltage dependence of inactivation was measured by $250 \mathrm{~ms}$ voltage steps, followed by a test pulse to $-20 \mathrm{mV}$ to measure availability. $B$, The availability as a function of voltage is plotted and fit with a first-order Boltzmann function. The half-inactivation voltage $\left(V_{\mathrm{h}}\right)$ was $-53.7 \mathrm{mV}$ and the slope factor $\left(V_{c}\right)$ was $5.0 \mathrm{mV}$ (the blue line is the third-order Boltzmann fit of activation conductance from Fig. 2C. C, The development of inactivation at subthreshold potentials was measured by voltage steps of increasing length and fit with double-exponential equations ( -70 , blue triangles; -60 , red triangles; -50 , green squares; -40 , black circles). $\boldsymbol{D}$, The recovery of inactivation is measured by hyperpolarizing steps of increasing length, followed by a test pulse to $-20 \mathrm{mV}$. Peak amplitudes as a function of time are best fit with a double exponential $(-100 \mathrm{mV}$, orange diamonds; $-90 \mathrm{mV}$, blue triangles; $-80 \mathrm{mV}$, green triangles; -70 , red squares; $-60 \mathrm{mV}$, black circles). $\boldsymbol{E}$, The decay of the sodium current generated by a step to $-30 \mathrm{mV}$ is most accurately fit with a double-exponential function (top trace, blue line). Decay at $0 \mathrm{mV}$ could more accurately be fit with a single-exponential function than the step to $-30 \mathrm{mV}$ (bottom trace, red line) but was still better fit with a doubleexponential function (blue line). $\boldsymbol{F}$, The fast and slow time constants (filled and open circles, respectively) for inactivation (measured from fits in Figs. $2 A$, inset, $3 C, D$ ) are plotted as a function of voltage (the gray line is the first-order Boltzmann fit from Fig. $3 B)$. The relative weight of the fast time constant at each voltage is plotted in the inset.

covery of inactivation near the foot of the activation curve were determined using standard multistep conditioning protocols. Plots of test step current as a function of time and voltage were best fit with biexponential equations (Fig. $3 C, D$ ). The fast and slow time constants from protocols were compiled into a single plot (Fig. $3 F$ ) and fit with a two-state model derived from the $\mathrm{HH}$ formalism. The relative amplitude of the fast and slow time constants varied only modestly with membrane voltage (Fig. 3F, inset). More importantly, the fast inactivation time constants here closely resemble those of neurons not capable of fast spiking (Martina and Jonas, 1997; Maurice et al., 2004). Hence, if these channels are distinctive, it is in some property other than fast inactivation.

\section{Slow inactivation of $\mathrm{Na}^{+}$channels was} similar to that in other neurons

Another mechanism that reduces the availability of $\mathrm{Na}^{+}$channels is slow inactivation. Membrane depolarization promotes channel entry into this nonconducting state (Jung et al., 1997; Mickus et al., 1999; Carr et al., 2003; Chen et al., 2006). Thus, slow inactivation could be particularly important for GPe neurons that, like their neighbors in the STN, spike at high rates and maintain relatively depolarized membrane potentials (Do and Bean, 2003). Entry of channels into the slow inactivated state from the fast inactivated state was studied using long depolarizing steps, whereas entry from the open state was examined with trains of short pulses (5 ms step to $-20 \mathrm{mV}$ at $20 \mathrm{~Hz}$ ). Occupancy in the slow inactivated states was estimated by measuring channel availability after a $1 \mathrm{~s}$ step to $-80 \mathrm{mV}$, a sufficient time to allow full recovery from fast inactivation. During pulse trains, entry of channels into the slow inactivated state from the open state occurred with a time constant of $4.5 \pm 1.0 \mathrm{~s}$ and reached $\sim 20 \%$ within $15 \mathrm{~s}$. With steps to $-20 \mathrm{mV}$ (rather than pulse trains), the time constant describing entry into the slow inactivated state was comparable $(4.0 \pm 0.5 \mathrm{~s})$, but steps inactivated significantly more $\mathrm{Na}^{+}$ channels after $15 \mathrm{~s}$ and inactivation continued to grow if the step was maintained (Fig. 4A). However, if only the time spent at depolarized membrane potentials was used to estimate the entry time constant, the entry rate appeared to be 10 times faster from the open state (during a pulse) than from the fast-inactivated state (during a step). So, there was less slow inactivation during a pulse train only because the time spent by channels in a permissive open state was less than that for an equal duration step.

The voltage dependence of slow inactivation was estimated using $5 \mathrm{~s}$ conditioning steps. Although slow inactivation had not reached steady state by $5 \mathrm{~s}$, this pulse length allowed a range of voltages to be examined before the quality of the recording had deteriorated. These data were reasonably fit with a single Boltzmann function having a half-inactivation voltage of $-50.4 \pm 2.6 \mathrm{mV}$ and a slope factor of $20 \pm 2 \mathrm{mV}$ (Fig. $4 B$ ). 
A
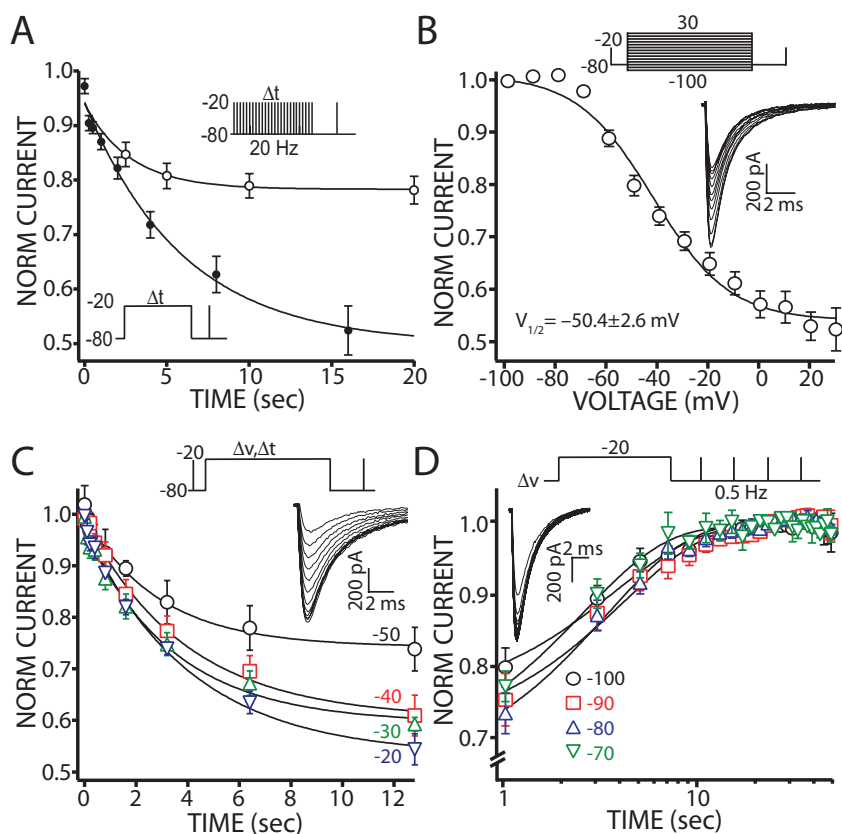

$E$
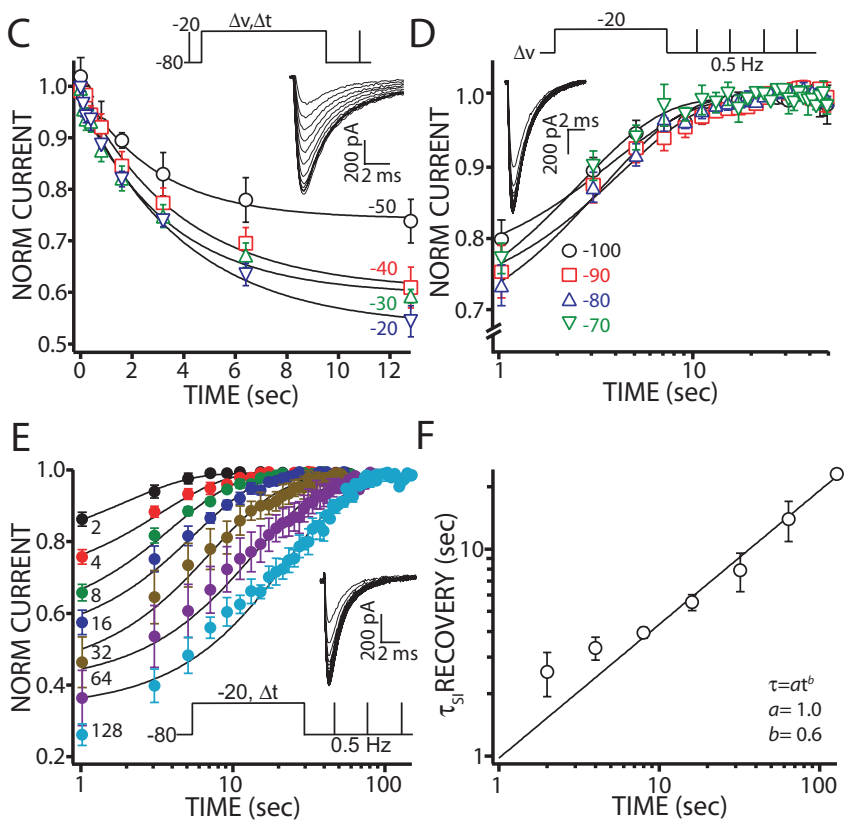

$\mathrm{F}$

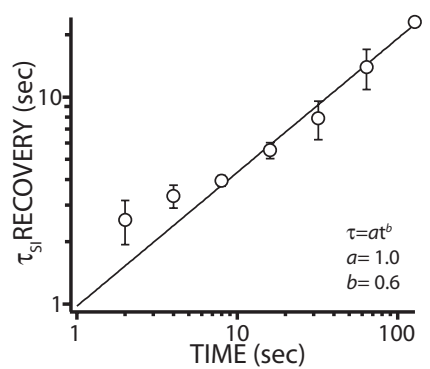

Figure 4. GPe $\mathrm{Na}^{+}$channels undergo slow inactivation during extended periods at depolarizing potentials or long trains of depolarizing pulses. $\boldsymbol{A}$, Slow inactivation can be generated by both prolonged steps to depolarized potentials (filled circles) and trains of brief pulses (open circles), as measured by test pulses after increasing lengths of pulses or trains. The time constants for development during the pulse trains and steps are $4.5 \pm 1$ and $4.0 \pm 0.5 \mathrm{~s}$, respectively. $\boldsymbol{B}$, The pseudo-steady state of slow inactivation after $5 \mathrm{~s}$ is measured by a test pulse $1 \mathrm{~s}$ after an inactivating step. The peak current is plotted as a function of voltage and fit with a first-order Boltzmann equation. The half-inactivation voltage at this time point is $-50.4 \pm 2.6$ $\mathrm{mV}$, with a slope factor of $20 \pm 2 \mathrm{mV}$. Calibration: for traces (inset), $200 \mathrm{pA}, 2 \mathrm{~ms}$. C, The kinetics of entry into the slow inactivated state are not voltage dependent $(-50 \mathrm{mV}, 4.0 \pm 2.1 \mathrm{~s} ;-40$ $\mathrm{mV}, 4.3 \pm 0.7 \mathrm{~s} ;-30 \mathrm{mV}, 3.7 \pm 0.5 \mathrm{~s} ;-20 \mathrm{mV}, 4.0 \pm 0.5 \mathrm{~s} ; n=5)$. Calibration: for traces (inset), $200 \mathrm{pA}, 2 \mathrm{~ms}$. D, The kinetics of recovery from slow inactivation are not voltage depen$\operatorname{dent}(-100 \mathrm{mV}, 4.0 \pm 0.6 \mathrm{~s} ;-90 \mathrm{mV},-3.9 \pm 0.7 \mathrm{~s} ;-80 \mathrm{mV}, 3.7 \pm 0.5 \mathrm{~s} ;-70 \mathrm{mV}, 3.2 \pm$ $0.7 \mathrm{~s} ; n=5$ ). Calibration: for traces (inset), $200 \mathrm{pA}, 2 \mathrm{~ms}$. $\boldsymbol{E}$, The recovery from slow inactivation is measured by test pulses every $2 \mathrm{~s}$ after increasing lengths of inactivating steps to $-20 \mathrm{mV}$ ( 2 s, black; $4 \mathrm{~s}$, red; $8 \mathrm{~s}$, green; $16 \mathrm{~s}$, navy blue; $32 \mathrm{~s}$, brown; $64 \mathrm{~s}$, purple; $128 \mathrm{~s}$, sky blue). Calibration: for traces (inset), 200 pA, 2 ms. $\boldsymbol{F}$, The time constants for recovery as a function of time at inactivating voltage obeyed a power law with $\tau=\mathrm{t}^{0.6}$, where $t$ is the length of the step to -20 $\mathrm{mV}$.

Although the amount of slow inactivation appeared to show a dependence on voltage, the kinetics of entry and recovery from this state did not. Unlike fast inactivation, in which entry into the fast-inactivated state was faster at more depolarized potentials and recovery was faster at more hyperpolarized potentials, the kinetics of slow inactivation were similar throughout the voltage range. With a step to $-20 \mathrm{mV}$, slow inactivation developed with a time constant of $4.0 \pm 0.5 \mathrm{~s}$, whereas at $-50 \mathrm{mV}$, the time constant of development was $4.0 \pm 0.6 \mathrm{~s}$ (Fig. $4 \mathrm{C}$ ). At $-80 \mathrm{mV}$, the time constant of recovery from a $5 \mathrm{~s}$ step was $3.7 \pm 0.5 \mathrm{~s}$, and, at $-100 \mathrm{mV}$, it was $4.0 \pm 0.6 \mathrm{~s}$ (Fig. $4 D$ ).
In hippocampal dentate granule cells, the recovery from slow inactivation is dependent on the length of step used to produce inactivation. The longer the time spent at a depolarized potential, the slower the recovery kinetics (Ellerkmann et al., 2001). Recovery from slow inactivation in GPe neurons was also dependent on inactivating step length. Plotting the time constant of recovery as a function of prepulse duration revealed a power law relationship of the form $\tau=\mathrm{t}^{0.6}$, where $t$ is the length of the inactivating step to $-20 \mathrm{mV}$ (Fig. $4 E, F$ ). The deviation from the power law function at short prepulse durations was likely a measurement artifact because there is a greater proportion of recovery from slow inactivated states during the first second of short prepulses that is not measurable in the protocol.

\section{Persistent and resurgent $\mathrm{Na}^{+}$currents are prominent in GPe neurons}

The biophysical tests to this point have not revealed anything about $\mathrm{Na}^{+}$channels in GPe neurons that indicates they are tailored to allow fast spiking or autonomous spiking. Two other gating modes linked to repetitive spiking were examined. Persistent $\mathrm{Na}^{+}$channel gating has a well characterized role in shaping excitability and action potential generation (Pennartz et al., 1997; Bevan and Wilson, 1999; Agrawal et al., 2001; Taddese and Bean, 2002; Do and Bean, 2003). In addition to persistence, $\mathrm{Na}^{+}$channels in Purkinje and other fast-spiking neurons display a gating mode that leads to a resurgent current during repolarization of the membrane after a spike (Raman and Bean, 1997, 1999; Raman et al., 2000; D'Angelo et al., 2001; Do and Bean, 2003; Afshari et al., 2004; Cummins et al., 2005; Enomoto et al., 2006; Magistretti et al., 2006). Both subthreshold persistent and resurgent $\mathrm{Na}^{+}$currents were present in GPe neurons. The persistent current was present in the voltage range in which activation of $\mathrm{Na}^{+}$channels had begun but inactivation was incomplete. During a $4 \mathrm{~s} \mathrm{ramp}$ from -80 to $0 \mathrm{mV}$, persistent current was evident above $-65 \mathrm{mV}$ and peaked at $-40 \mathrm{mV}\left(I_{\max }=55.3 \pm 6.4 \mathrm{pA}\right.$ in physiological concentrations of external Na${ }^{+}$) (Fig. 5A). This is the voltage range between the trough of the afterhyperpolarizing potential $(-68 \pm 1 \mathrm{mV} ; n=11)$ and spike threshold $(-51 \pm 1$ $\mathrm{mV} ; n=11)$ in GPe neurons, suggesting that $\mathrm{Na}^{+}$channel persistent currents are well suited to a role in driving autonomous pacemaking.

Resurgent current has typically been found in neurons that fire at high rates, either in bursts or rhythmically (Afshari et al., 2004). Resurgence is thought to result from the exit of a blocking particle during membrane repolarization; the particle appears to have access to its binding site only when the channel is open and once bound prevents the channel from undergoing fast inactivation (Khaliq et al., 2003). GPe neurons displayed a prominent resurgent $\mathrm{Na}^{+}$current with kinetics similar to those described in Purkinje and STN neurons (Fig. 5B-E) (Do and Bean, 2003; Khaliq et al., 2003). Slow inactivation reduced transient, persistent, and resurgent currents to similar extents (Fig. 5F).

\section{Neurons lacking the Nav1.6 subunit display reduced resurgence}

In Purkinje neurons from Nav1.6 null mice, resurgent $\mathrm{Na}^{+}$current is virtually lost, and there is a significant reduction in autonomous spiking and the ability to spike at high rates (Raman and Bean, 1999; Khaliq et al., 2003). In STN neurons, loss of Nav1.6 channels leads to a less drastic reduction in resurgence and no change in autonomous spiking or fast-spiking capacity (Do and Bean, 2004). In acutely isolated GPe neurons from Nav1.6 null mice, there was a prominent $(\sim 40 \%)$ reduction in the amplitude 
A

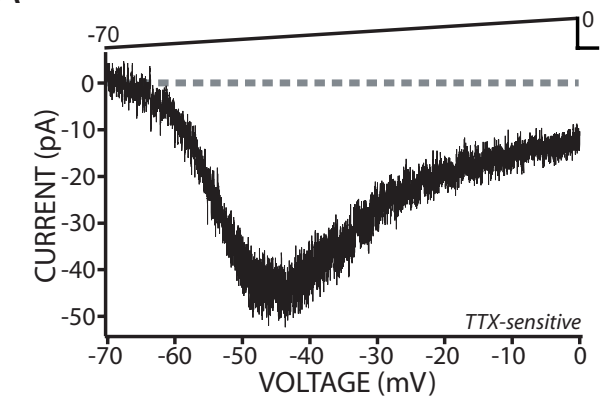

B
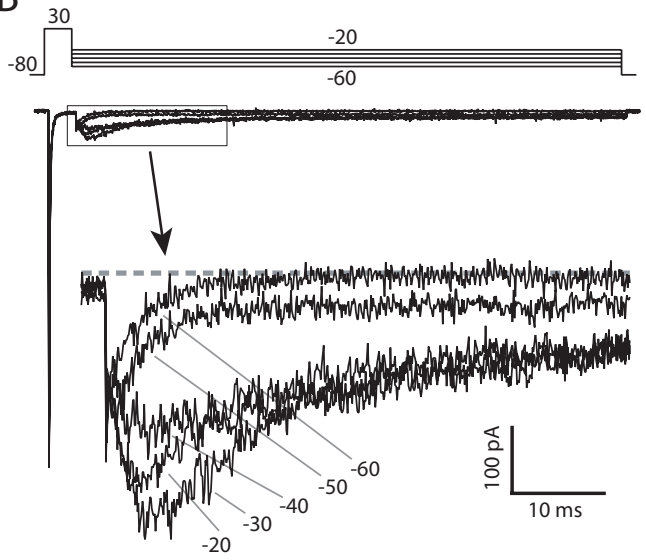

C
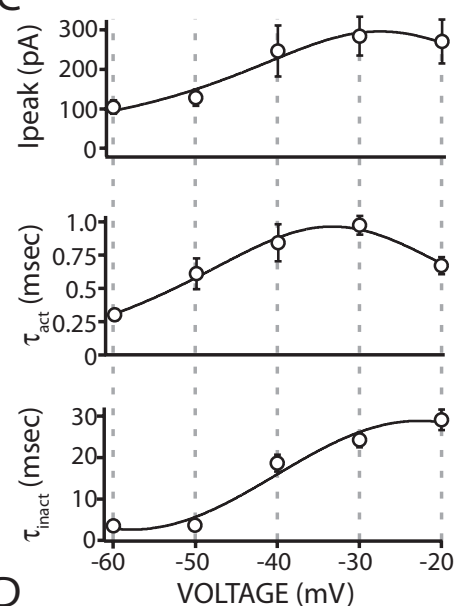

D

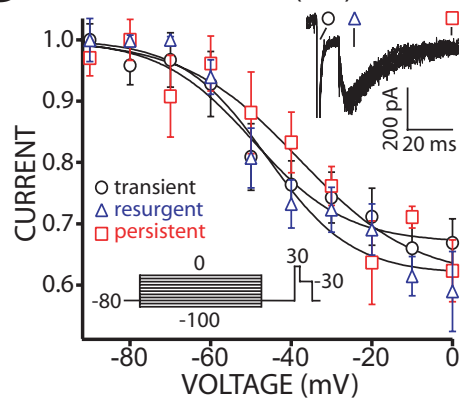

Figure 5. $\mathrm{Na}^{+}$channels in the GPe conduct both persistent and resurgent currents. $\boldsymbol{A}$, The persistent current is generated by a 4 s ramp from -80 to $0 \mathrm{mV}$. $\boldsymbol{B}$, During repolarization of the membrane from depolarized potentials, a resurgent $\mathrm{Na}^{+}$current is conducted by channels. $C$, Top, The amplitude of resurgent current is plotted against repolarization potential. The amplitude peaks near $-30 \mathrm{mV}$ at 260 pA (median; for box plot, see Fig. 6 B). Middle, The time constant of activation is plotted against repolarization potential. The activation kinetics were approximately five times slower than the activation kinetics of the transient current. Bottom, The time constant of decay of the resurgent current as a function of repolarization potential. The kinetics were in the range of the slow time constant for fast inactivation. $\boldsymbol{D}$, Slow inactivation of transient (black circles, measured at depolarizing step to $+30 \mathrm{mV}$ ), resurgent (blue triangles, peak current during repolarization to $-30 \mathrm{mV}$ ), and persistent (red squares, steady-state current measured at end of repolarization step) are plotted as a function of prepulse potential and fit with a Boltzmann equation. The half-inactivation for transient, resurgent, and persistent currents were $-49 \pm 3,-45 \pm 5$, and $-51 \pm 2 \mathrm{mV}$, respectively, and the slope factors were $7 \pm 2,8 \pm 3$, and $6 \pm 1 \mathrm{mV}$.

of resurgent current (median amplitude of $260 \mathrm{pA}$ in wild-type neurons; 158 pA in Nav1.6 null neurons) (Fig. 6A,B).

In contrast, there was no discernible change in the amplitude of transient current in acutely isolated Nav1.6 null GPe neurons (Fig. $6 C$ ). Moreover, the steady-state voltage dependence of activation $\left(V_{\mathrm{h}}\right.$ of $-40.2 \pm 0.7 \mathrm{mV} ; V_{c}$ of $\left.8.4 \pm 0.2 \mathrm{mV}\right)$ and inactivation $\left(V_{\mathrm{h}}\right.$ of $-54.8 \pm 1.1 \mathrm{mV}$; $V_{c}$ of $\left.4.3 \pm 0.3 \mathrm{mV}\right)$ of the transient $\mathrm{Na}^{+}$channel current in Nav1.6 null neurons were not significantly different from wild-type neurons $(n=11 ; p>0.05$, Mann-Whitney rank sum test) (supplemental Fig. $2 A$, available at www.jneurosci.org as supplemental material). However, the rate at which channels underlying the transient current inactivated was significantly greater in Nav1.6 null neurons (Fig. 6D). Both fast and slow time constants of inactivation were smaller across a broad range of test potentials in neurons lacking functional Nav1.6 channels (Fig. 6E). Although fast inactivation was altered, slow inactivation was not discernibly different (supplemental Fig. $2 B$, available at www.jneurosci.org as supplemental material).

Last, the amplitude and the voltage dependence of the persistent current in GPe neurons from Nav1.6 null mice also were not distinguishable from those taken from wild-type mice when

viewed with slow voltage ramps (Fig. $6 F, G)$ or when those currents were converted to estimates of conductance as a function of voltage (Fig. $6 \mathrm{H}$ ). Fitting the rising phase of the conductance plots also failed to reveal any difference in currents after the loss of Nav1.6 channels (Nav1.6 nulls, $V_{\mathrm{h}}$ of $-42.2 \mathrm{mV}, V_{c}$ of $3.2 \mathrm{mV}, n=7$; wild-type, $V_{\mathrm{h}}$ of $-43.6 \mathrm{mV}, V_{c}$ of $3.2 \mathrm{mV}$, $n=12 ; p>0.05$, Mann-Whitney rank sum test).

\section{Loss of Nav1.6 channels slowed autonomous pacemaking and} diminished the response to intracellular current injection

Although transient and persistent currents were unchanged in acutely isolated GPe Nav1.6 null neurons, autonomous pacemaking of GPe neurons in tissue slices (in which dendrites and the axon initial segment/axon were essentially preserved) was dramatically slowed. Wild-type GPe neurons (taken from either littermates of Nav1.6 null mice or other C57BL/6 litters) spiked autonomously near $12 \mathrm{~Hz}$ in the intact slice at room temperature (C57BL/6 control mean, $12.7 \mathrm{~Hz}, n=110$; littermate mean, $12.0 \mathrm{~Hz}, n=14$ ), whereas Nav1.6 null neurons spiked at approximately half that rate (mean, $5.4 \mathrm{~Hz} ; n=75$ ) (Fig. $7 A, B$ ). The regularity of the discharge fell in parallel (Fig. $7 C)$. Consistent with the slowing, action potential threshold (as defined by the voltage at which there is a sudden change in voltage trajectory) during autonomous pacemaking was elevated by the loss of Nav1.6 channels, rising from $-51 \pm 1 \mathrm{mV}$ in wild-type neurons $(n=11)$ to $-44 \pm 1 \mathrm{mV}$ in Nav1.6 null neurons $(n=11 ; p<0.001$, Mann-Whitney rank sum test). Thresholds for eliciting single action potentials from a hyperpolarized potential $(-97 \mathrm{mV})$ also were statistically different (median spike threshold: wild type, -56.8 $\mathrm{mV}, n=10$; Nav1.6 null, $-52.2 \mathrm{mV}, n=30 ; p<0.001$, MannWhitney rank sum test) (Fig. $7 D, E$ ), suggesting that the change in threshold was not a consequence of increased channel inactivation.

Because resurgent $\mathrm{Na}^{+}$current is also thought to play an important role in fast spiking, maximal spiking rates of Nav1.6 null neurons were examined using current ramps. Wild-type neurons were typically able to sustain spiking throughout the ramp, attaining frequencies over $100 \mathrm{~Hz}$ (Fig. 7F). In contrast, none of the Nav1.6 null neurons were able to sustain spiking throughout the ramp and had significantly lower maximal firing frequencies (Fig. $7 F-H)$. As expected from the elevation in spike threshold, first spike latency of Nav1.6 null neurons was also longer than wildtype neurons (average first spike latency, $57 \pm 8 \mathrm{~ms}$ in wild type; $102 \pm 10 \mathrm{~ms}$ in Nav1.6 null; $p<0.001$, Mann-Whitney rank sum test). Last, as predicted from analysis of autonomous spiking, initial spike threshold (defined as the voltage at which there is an abrupt change in $d V / d t)$ was elevated in Nav1.6 null neurons when driven by the current ramps but other aspects of the spike trajectory were not discernibly altered (Fig. 7I). 
Loss of Nav1.6 channels leads to depolarization block in response to DBS-like stimulation

In contrast to regular spiking neurons, neurons with the capacity to sustain fast spiking should be able to faithfully follow electrical DBS at therapeutically effective frequencies $\left(90-120 \mathrm{~Hz}\right.$ at $\left.37^{\circ} \mathrm{C}\right)$. Most models of how HFS-DBS works in the basal ganglia are based on the assumption that the targeted neurons behave like regular spiking neurons and HFS-DBS produces depolarization block $\mathrm{Na}^{+}$channel inactivation) and cessation of spiking in the STN and GPe (Benabid et al., 2002). To test this hypothesis in GPe neurons, long trains of brief pulses ( $2 \mathrm{~ms}, 500 \mathrm{pA}$ ) were applied in the whole-cell configuration at $22^{\circ} \mathrm{C}$. At $50 \mathrm{~Hz}, \mathrm{GPe}$ neurons were fully capable of firing with every stimulus (Fig. $8 \mathrm{~A}$ ). At $100 \mathrm{~Hz}$, neurons followed stimuli for a while and then settled into a regular discharge at a "preferred" frequency near $50 \mathrm{~Hz}$ (Fig. 8 B). At $250 \mathrm{~Hz}$, GPe neurons again followed the stimulus train briefly and then settled into a regular discharge at their preferred frequency (Fig. 8C). Thus, high-frequency stimulation did not produce depolarization block and cessation of firing but rather sustained spiking at a preferred frequency (Fig. 8D). Because channel gating typically has a $Q_{10}$ of 2-3 (Hille, 2001), these results suggest that, at body temperature $\left(37^{\circ} \mathrm{C}\right)$, GPe neurons should be capable of sustained spiking at over 150 $\mathrm{Hz}$, well in excess of the $90-120 \mathrm{~Hz}$ that is therapeutically effective in PD patients (Benabid et al., 2002). In contrast, agematched Nav1.6 null GPe neurons were not capable of sustained high-frequency discharge (Fig. 8A-C). At $25 \mathrm{~Hz}$, Nav1.6 null neurons failed to follow stimulation faithfully. At higher stimulation rates, neurons fired spikes in a random, intermittent manner (Fig. 8D).

\section{Simulations suggest dissociable roles for Nav1.6 channels}

The experimental work illustrated thus far shows that the loss of functional Nav1.6 channels leads to three alterations in the physiology of GPe neurons: (1) an elevation in spike threshold, (2) a slowing of autonomous pacemaking rate, and (3) a reduction in the ability to spike at high rates. To better understand the linkage between Nav1.6 channels and these changes, a model of GPe neurons was constructed using the NEURON platform (Hines and Carnevale, 2001). To capture the gating behavior of Nav1.6 and Nav1.1/1.2 channels, two multistate Markov models were constructed. Both models had a topology similar to previous models (Kuo and Bean, 1994; Carr et al., 2003) but added blocked (resurgent) states (Khaliq et
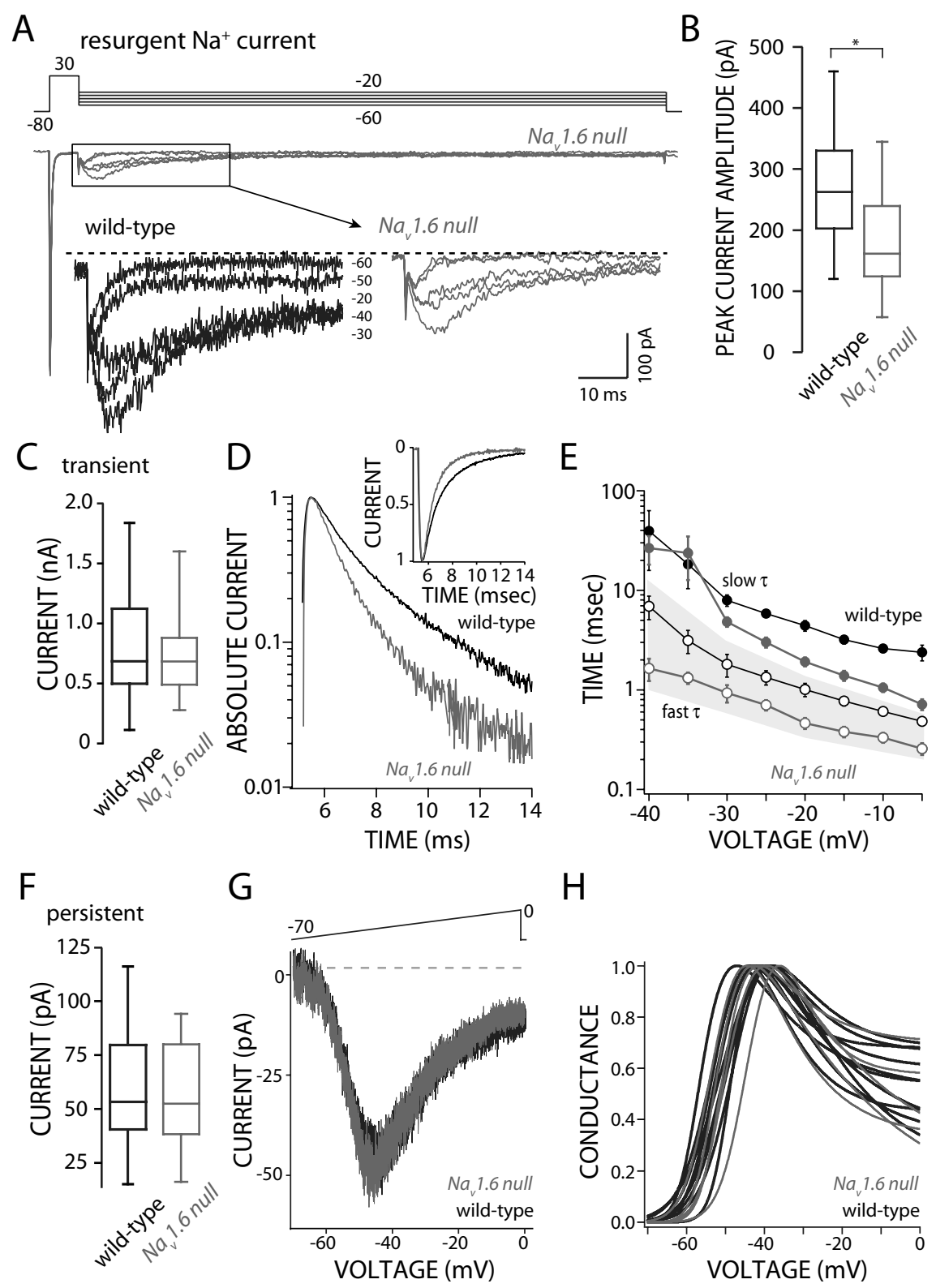

$\mathrm{H}$

Figure 6. $\mathrm{Na}^{+}$channels from Nav1.6 null GPe neurons exhibit a reduced resurgent current and an accelerated decay of the transient current but no reduction in transient or persistent current amplitudes. $\boldsymbol{A}$, Representative traces of resurgent currents from wild-type (black, from Fig. 5B) and Nav1.6 null (gray) GPe neurons, measured in physiologic external $\mathrm{Na}^{+}$in whole-cell voltage clamp of dissociated neurons. $\boldsymbol{B}$, Box plots of resurgent current amplitude in dissociated GPe neurons from WT (left) and Nav1.6 null (right). The median amplitude, measured as peak from baseline at $-30 \mathrm{mV}$, for wild type is $260 \mathrm{pA}(n=37)$, whereas the median for Nav1.6 null GPe neurons is reduced $40 \%$ to $158 \mathrm{pA}\left(n=11 ;{ }^{*} p<0.05\right.$, Mann-Whitney rank sum test). C, Box plot of transient current amplitudes of wild-type (black) and Nav1.6 null (gray) neurons. Median current amplitude from wild-type and Nav1.6 null neurons were 673.5 and $667.6 \mathrm{pA}$, respectively ( $p>0.05$, Mann-Whitney rank sum test). $\boldsymbol{D}$, Representative traces of transient current elicited by a test step to $-20 \mathrm{mV}$. Current was normalized and plotted on a logarithmic scale to show the difference in inactivation kinetics between wild-type (black) and Nav1.6 null (gray) neurons. Inset shows the same traces plotted on a linear timescale. $\boldsymbol{E}$, Fast (open circles in gray shadow) and slow (filled circles) time constants of fast inactivation in wild-type (black) and Nav1.6 null (gray) neurons. $\boldsymbol{F}$, Box plot of persistent current amplitudes of wild-type (black) and Nav1.6 null (gray) neurons. Median current amplitudes for wild type and Nav1.6 null were 52.1 and $51.9 \mathrm{pA}$, respectively ( $p>0.05$, Mann-Whitney rank sum test). $\mathbf{G}$, Representative traces of persistent current from wild-type (black) and Nav1.6 (gray) neurons elicited by a $4 \mathrm{~s}$ ramp from -70 to $0 \mathrm{mV}$. $\boldsymbol{H}$, Conductance measurements of persistent currents measured in a sample of wild-type (black lines) and Nav1.6 null (gray lines) neurons show considerable overlap.

al., 2003) and had multiple slow inactivated states that partially capture the power law behavior of slow inactivation (supplemental Fig. $3 A$, available at www.jneurosci.org as supplemental material). The modNavl.1 accurately reproduced the currents seen in Nav1.6 null GPe neurons (those conducted by Nav1.1 and 
A autonomous pacemaking

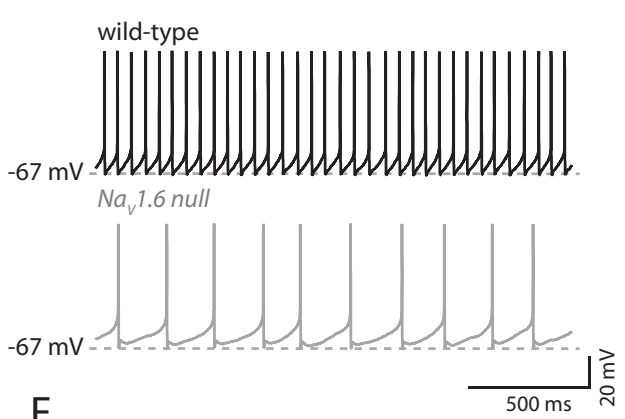

\section{F}

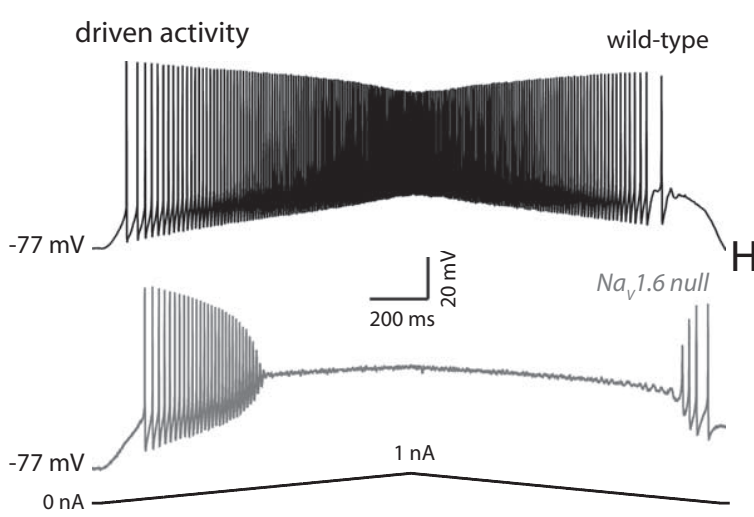

C

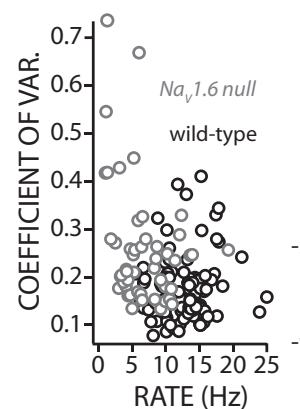

$\mathrm{G}$
B

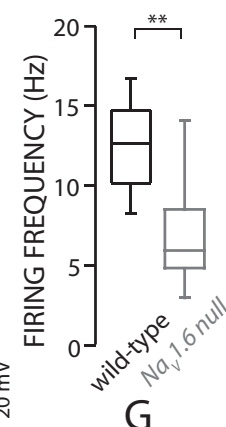

D

evoked action potential wild-type $\mathrm{Na}_{\mathrm{v}} 1.6$ null
E

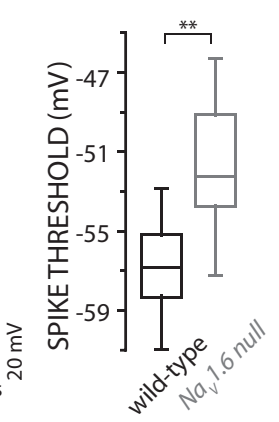

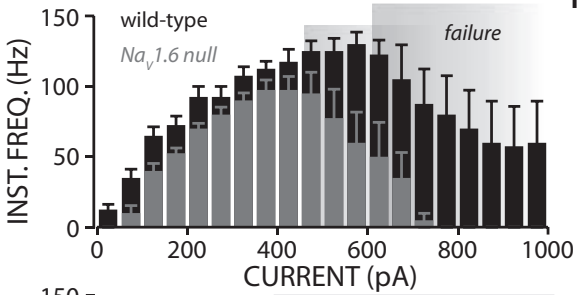
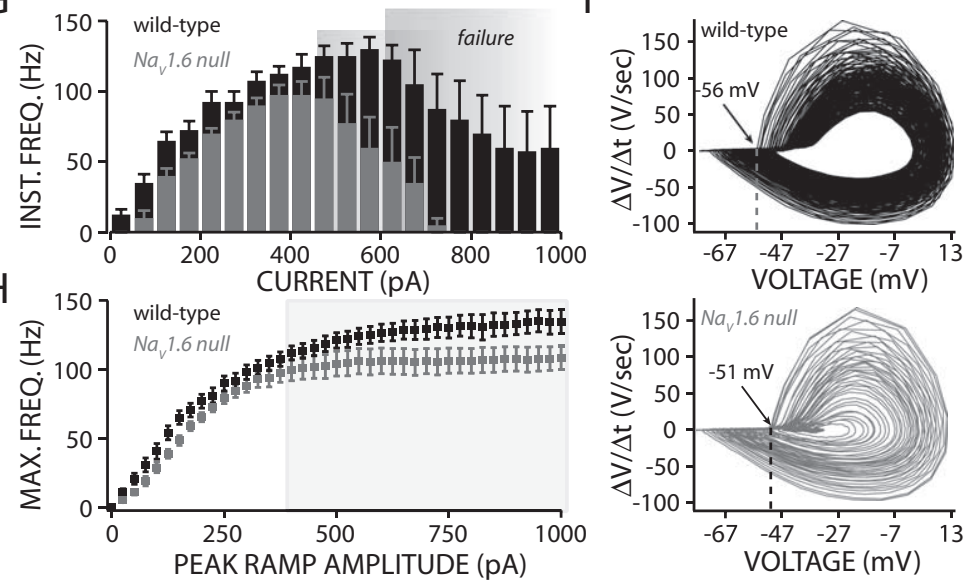

Figure 7. Nav1.6 null GPe neurons have reduced autonomous pacemaking, peak driven firing frequencies, and an elevated spike threshold. $A$, Voltage traces of autonomous activity in wild-type (black, top trace) and Nav1.6 null (gray, bottom trace) GPe neurons recorded under whole-cell current clamp in intact slices. B, Autonomous firing rate of wild-type (median of 12.6 Hz; $n=124$ ) and Nav1.6 null (right; median of $5.4 \mathrm{~Hz} ; n=75)$ GPe neurons, as measured in the non-invasive, tight-seal, cell-attached mode, were significantly different $\left({ }^{* *} p<0.01\right.$, Mann-Whitney rank sum test). C, Relationship between the discharge rate and the regularity of discharge (coefficient of variation) in wild-type (black) and Nav1.6 null (gray) neurons. D, Sample traces of a single action potential from wild-type (black, top trace) and Nav1.6 null (gray, bottom trace) neurons were elicited from $-97 \mathrm{mV}$ under whole-cell current clamp in intact slices. $E$, Spike thresholds measured from wild-type and Nav1.6 null GPe neurons held at $-97 \mathrm{mV}$ were significantly different ( ${ }^{* *} p<0.01$, Mann-Whitney rank sum test; median spike threshold: wild type, $-56.8 \mathrm{mV}, n=10$; Nav1.6 null, $-52.2 \mathrm{mV}, n=30$ ). $\boldsymbol{F}$, Voltage traces from a wild-type (black) and Nav1.6 null (gray) neuron during a $1 \mathrm{~s}$ ramp to $1 \mathrm{nA}$ current. The ramp protocol was $2 \mathrm{~s}$ long, evoked from $-77 \mathrm{mV}$ : $1 \mathrm{~s}$ depolarizing to $1 \mathrm{nA}$ and $1 \mathrm{~s}$ relaxing back to $0 \mathrm{pA}$ injected current. G, Population distribution histogram of instantaneous discharge frequency as a function of current amplitude during a $1 \mathrm{nA}$ ramp showing a decrease in maximal firing rate attained by Nav1.6 null and the increase of failure (shaded area) during high current injection. $\boldsymbol{H}$, Maximum firing frequency as a function of current amplitude of a $1 \mathrm{~s}$ ramp to varying peak current injections reveals a depression in maximum frequency reached in Nav1.6 null neurons (mean \pm SEM, $99.7 \pm 7.8 \mathrm{~Hz}$ ) versus wild-type neurons (mean \pm SEM, $129.6 \pm 10 \mathrm{~Hz} ; p<0.05$, Mann-Whitney rank sum test; $n=8$ ). II, Phase plot of spikes during the ramp protocol, generated by plotting the derivative of the voltage as a function of membrane potential. Note the difference in first spike threshold and the drastic shift during the ramp protocol in the Nav1.6 null neuron. Also note the similarity in the rest of the spike trajectory.

Nav1.2 channels combined). The second channel model, referred to as modNav1.6, was added to the first at an appropriate ratio to give an accurate reproduction of the wild-type $\mathrm{Na}^{+}$currents (supplemental Fig. 3B-F, available at www.jneurosci.org as supplemental material).

To generate an estimate of how the availability of each $\mathrm{Na}^{+}$ channel changed during pacemaking and DBS, channels were inserted into a spherical soma and the membrane potential driven with a simulated patch electrode. First, channel availability during pacemaking was studied. Using the voltage trajectory of a GPe neuron pacemaking at $12 \mathrm{~Hz}, \mathrm{Na}^{+}$channel state was monitored by measuring the probability of being in closed or open (not inactivated) states. The availability of modNav1.6 channels exceeded $60 \%$ as the membrane potential approached spike threshold, whereas that of modNav1.1 channels was less than half that (Fig. 9C, left). The availability differences between the two channel models during pacemaking were primarily attributable to the resurgent gating mode. In the first $2 \mathrm{~ms}$ after the repolarization of the spike, the Nav1.6 channel recovers much faster than the modNav1.1 channel. When resurgent gating was eliminated in the Nav1.6 model (by changing $O b_{0}$ to $1 e-9$ and
Oon to 5 for both channel types), availability of the two channels during the pacemaking cycle was very similar (data not shown).

The difference in channel availability also was seen during DBS-like stimulation. Using the voltage of a GPe neuron recorded during the experiments described above, channel availability was monitored. At $50 \mathrm{~Hz}$, modNav1.6 channel availability fluctuated between 10 and $40 \%$, whereas modNav1.1 channels were much less available and never exceeded $\sim 10 \%$ (Fig. 9C, right). Again, this difference was primarily attributable to resurgent gating, because reducing this mode shifted modNav1.6 availability to very near that of the modNav1.1 channels during DBS-like stimulation (data not shown).

To gain a better understanding of how these differences in channel behavior contributed to spiking, a more anatomically correct model was created that had an axon, AIS, soma, and four primary dendrites (see Materials and Methods). Because previous localization studies have shown that modNav1.6 channels are found primarily in the axon and AIS, these regions were populated with modNav1.6 channels, whereas the dendrites and soma were primarily populated with modNav1.1 channels (the somatic ratio of Nav1.1/Nav1.6 channels was 4 , to match the inferred 
ratio seen in recordings from acutely isolated neurons). To reproduce normal spiking, previously described $\mathrm{K}^{+}, \mathrm{Ca}^{2+}$, and cationic ( $\mathrm{HCN})$ channels were inserted into the model to yield autonomous pacemaking at $\sim 12 \mathrm{~Hz}$ at $22^{\circ} \mathrm{C}$ (see Materials and Methods) (Fig. 10A). The trajectory of the somatic voltage in the model during pacemaking strongly resembled that seen in real GPe neurons (Fig. 10 A).

The simulations yielded two key insights into the functional role of Nav1.6 channels. First, the diminished pacemaking rate seen in Nav1.6 null neurons was attributable to the location of the channels, not their gating. Eliminating modNav1.6 channels from the model slowed autonomous spiking, as in the Nav1.6 null neurons (Fig. $10 \mathrm{~A}$, middle), but replacing modNav1.6 channels with modNav1.1 channels restored pacemaking into a normal range (Fig. 10A, bottom). Although the model did not capture the sharp rate of rise of the spike in somatic recordings that allowed unequivocal determination of spike threshold, apparent spike threshold clearly tracked channel density in the AIS (data not shown). Thus, channel density in the AIS and axon, rather than channel type, was the key determinant of basal pacemaking. In contrast, modNav1.6 channels, and resurgent gating, were critical to the ability to spike at high rates. Driving the model with a current ramp like that used experimentally (Fig. 7) led to steadily rising spike frequency in the model of wild-type neurons; deleting modNav1.6 channels dramatically diminished the capacity to spike at high frequencies, leading to frank failure in spike generation (Fig. $10 B-D$ ). Replacing modNav1.6 channels with modNav1.1 channels failed to restore the fast-spiking capacity of the model (Fig. $10 B-D$ ). These simulations clearly implicate Nav1.6 channels and the resurgent gating mode in determining the capacity to spike at high frequencies and suggest that the effects of genetic deletion of Nav1.6 on pacemaking are dependent on location of the channel, not gating.

\section{Discussion}

\section{Resurgent gating distinguishes $\mathrm{GPe} \mathrm{Na}{ }^{+}$channels}

Our studies revealed that $\mathrm{Na}^{+}$channels in GPe neurons were distinguished from those found in many regular spiking neurons by a prominent resurgent gating mode. This gating mode is believed to arise from a blocking particle that competes with the inactivation gate for the intracellular pore of the $\mathrm{Na}^{+}$channel at depolarized potentials (Raman and Bean, 2001; Grieco et al., 2005). During repolarization, the blocking particle releases at potentials at which kinetics of deactivation and inactivation are slow, enabling a brief return to the open state and the generation of a "resurgent" current before closing of the activation or inactivation gates. This gating mode is also found in $\mathrm{Na}^{+}$channels expressed in other autonomous pacemakers of the basal ganglia (Do and Bean, 2003; Surmeier et al., 2005) and cerebellum (Afshari et al., 2004). Although not exclusively associated with chan-
B
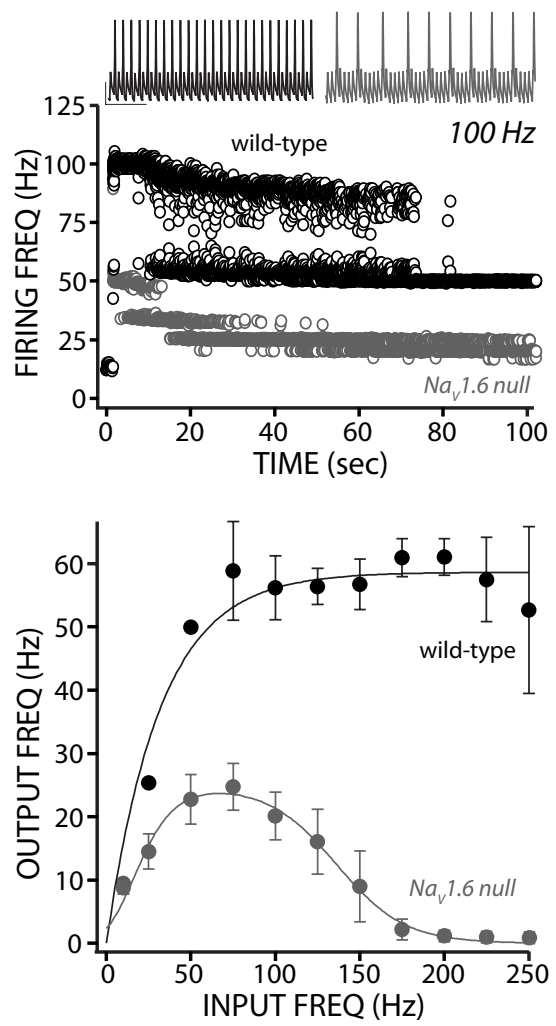

Figure 8. High-frequency stimulation identifies a preferred spike frequency near $50 \mathrm{~Hz}$ in wild-type neurons at room tempermaintaining firing near $50 \mathrm{~Hz}$, regardless of the stimulus frequency, whereas Nav1.6 null neurons (gray circles) were incapable of keeping up with the stimulus at frequencies as low as $25 \mathrm{~Hz}$ and became unresponsive to the stimulus at high frequencies.

nels possessing an Nav1.6 pore-forming subunit, resurgent gating appeared to be particularly common in this channel type.

The loss of functional Nav1.6 channels led to an elevation in spike threshold, a slowing of pacemaking, and a diminished capacity to spike at high frequencies. Computer simulations based on biophysically accurate channel models clearly indicated that the effects on spike threshold and pacemaking were not tightly linked to resurgent gating but rather to the likely positioning of Nav1.6 channels in spike initiating regions of the cell (AIS, axonal node) (Stuart et al., 1997; Boiko et al., 2001, 2003; Palmer and Stuart, 2006). In contrast, resurgent gating was critical to maintaining $\mathrm{Na}^{+}$channel availability during fast-spiking and highfrequency, DBS-like stimulation.

\section{Most gating properties of $\mathrm{GPe} \mathrm{Na}^{+}$channels were similar to those in regular spiking neurons}

In contrast to studies of other fast-spiking neurons (Martina and Jonas, 1997), our voltage-clamp analysis of $\mathrm{Na}^{+}$channel gating in acutely isolated GPe neurons failed to identify significant deviations in the macroscopic kinetics and voltage dependence of activation and fast inactivation from those found in regular spiking neurons. Furthermore, slow inactivation of $\mathrm{GPe} \mathrm{Na}^{+}$channels was not discernibly different in voltage dependence or kinetics from that seen previously in regular spiking pyramidal neurons (Ellerkmann et al., 2001). As in pyramidal neurons, the 
A model

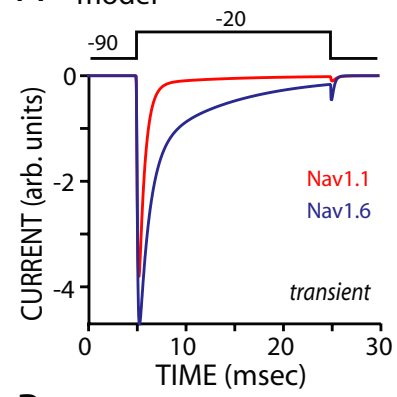

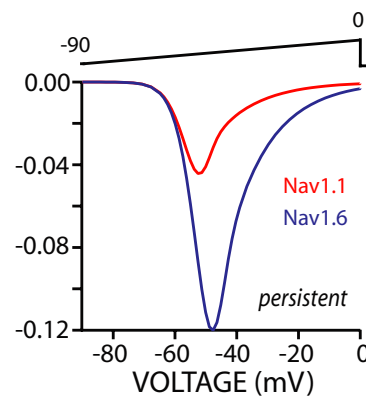

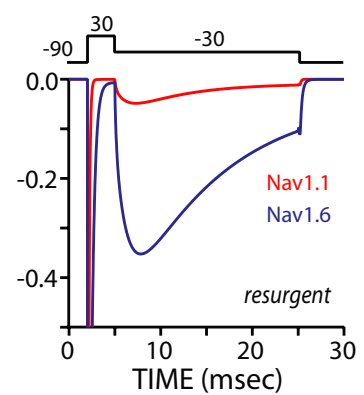

B Voltage command (experimental data)
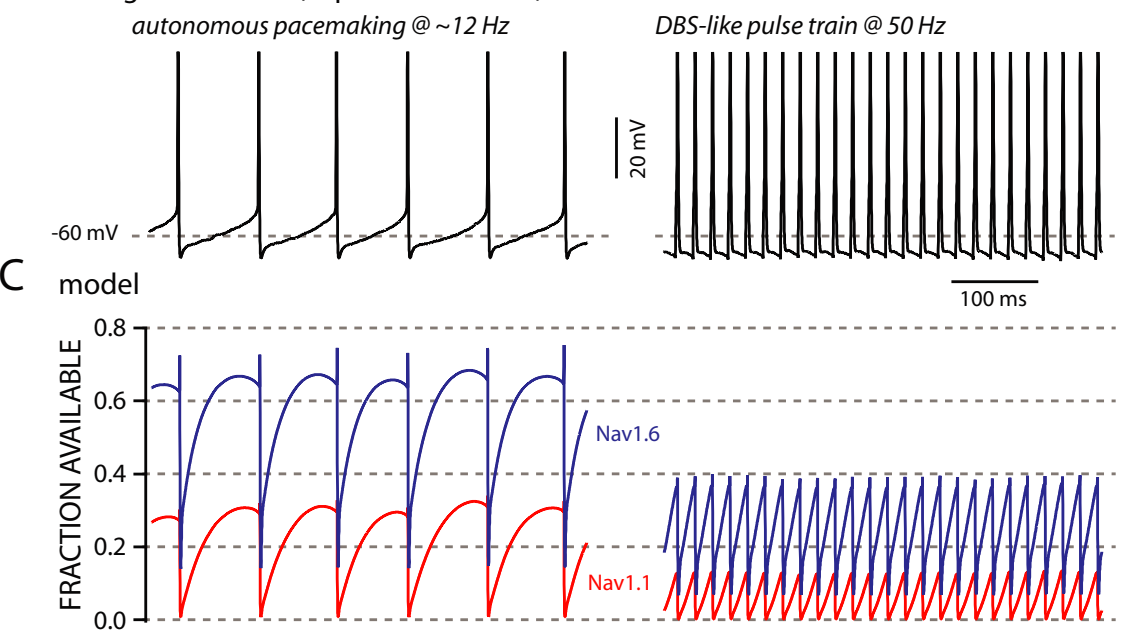

Figure 9. Two $\mathrm{Na}^{+}$channel model of wild-type and Nav1.6 null neurons. $\boldsymbol{A}$, Transient (left), persistent (middle), and resurgent (right) current traces generated by modNav1.1 (red) and modNav1.6 (blue) channels at equal densities. $\boldsymbol{B}$, Voltage records from a representative GPe neuron were used as voltage commands to estimate the availability (as sum of channels in the 0 and $\mathrm{C}_{1-5}$ states) of model $\mathrm{Na}^{+}$channels. Action potentials were truncated for clarity. C, Steady-state availability of modNav1.1 (red) and modNav1.6 (blue) channels during basal autonomous firing at $12 \mathrm{~Hz}$ (left), as well as that during driven activity (with intracellular current pulses) at $50 \mathrm{~Hz}$.

recovery from slow inactivation obeyed a power law rule with an exponent near 0.6.

\section{Nav1.6 channels and resurgent gating enable pacemaking and sustained fast spiking}

The frequency of autonomous activity in GPe neurons was closely tied to the availability of $\mathrm{Na}^{+}$channels, because TTX slowed spiking in a dose-dependent manner. In simulations of pacemaking in GPe neurons, a graded reduction in $\mathrm{Na}^{+}$channel density also produced a similar graded reduction in pacemaking rate, arguing that TTX was not preferentially blocking one type of channel. When it has been examined carefully, spike initiation appears to take place in either the AIS or the neighboring nodes (Colbert and Johnston, 1996; Fohlmeister and Miller, 1997; Stuart et al., 1997; Colbert and Pan, 2002; Clark et al., 2005; Palmer and Stuart, 2006; McCormick et al., 2007; Meeks and Mennerick, 2007). Localization studies have shown the AIS and axon nodes to be enriched in Nav1.6 channels (Caldwell et al., 2000; Krzemien et al., 2000; Tzoumaka et al., 2000; Boiko et al., 2001, 2003; Wittmack et al., 2004). If this is the case in GPe neurons, it is not surprising that transient and persistent $\mathrm{Na}^{+}$channel currents were not significantly altered in acutely isolated Nav1.6 null neurons, in which these regions are essentially lost. Nevertheless, the smaller resurgent current in these cells argues that Nav1.6 channels are normally present in the somatic membrane to some extent, and their loss in $\mathrm{med}^{T G}$ neurons appears to have been par-

tially compensated for by upregulation of Nav1.1 and/or Nav1.2 channels. This compensation is only partial, however. The rate of autonomous pacemaking and spike threshold were both depressed in Nav1.6 null neurons. A similar depression of autonomous pacemaking is seen in Purkinje neurons from Nav1.6 null mice (Khaliq et al., 2003; Levin et al., 2006). Our simulations showed that the loss of Nav1.6 channels in the AIS and axonal nodes could mimic the change in pacemaking seen in Nav1.6 null neurons. Importantly, in the simulations, replacement of these channels with Nav1.1 channels having much less resurgent gating completely restored pacemaking rate, suggesting that the position of these channels, not their distinctive gating, was critical for this aspect of GPe neuronal function. This result also argues that GPe neurons are autonomous pacemakers not because they express a special $\mathrm{Na}^{+}$channel but rather because they lack a countervailing $\mathrm{K}^{+}$ channel to oppose the drive of $\mathrm{Na}^{+}$channel currents to spike threshold. For example, in cortical pyramidal neurons, which do not normally spike in the absence of synaptic depolarization, partial blockade of Kir2 $\mathrm{K}^{+}$channels transforms them into autonomous pacemakers (Day et al., 2005).

In contrast to the situation in GPe and Purkinje neurons, the pacemaking and driven activity of STN neurons appears not to be affected by the loss of Nav1.6 channels (Do and Bean, 2004). It is not clear why this is the case. The most straightforward conclusion is that these neurons are qualitatively different from GPe and Purkinje neurons. However, one of the difficulties in working with Nav1.6 null $\left(\right.$ med $\left.^{T G}\right)$ mice is that they do not survive into adulthood. Because the insertion of Nav1.6 channels into the AIS and axon is developmentally regulated, increasing with age (Caldwell et al., 2000; Boiko et al., 2001, 2003; Van Wart and Matthews, 2006), it is possible that the difference between STN and GPe neurons is the timing of this switch to Nav1.6 channels. Reducing Nav1.6 channel expression in wildtype adult neurons with RNA interference strategies should allow this hypothesis to be tested.

\section{Resurgent gating is critical to fast spiking}

In contrast to pacemaking, resurgent gating was critical to fast spiking. To maintain spiking at high rates, $\mathrm{Na}^{+}$channels cannot enter into states that prevent opening and are difficult or slow to exit from. After a spike, channels leave the blocked state 10 times faster than they leave the fast inactivated state, maximizing their contribution to the next spike (and generating a resurgent current). Again, computer simulations showed that simply replacing Nav1.6 channels with ones in which resurgent gating was less prominent profoundly reduced the ability to spike at high frequency, in agreement with previous results (Khaliq et al., 2003). One potentially significant difference between the behavior of GPe neurons and Purkinje neurons from Nav1.6 null mice was spiking at intermediate frequencies. In GPe neurons, there were only modest consequences 
of Nav1.6 deletion until neurons were spiking at near maximal rates, in contrast to the situation in Purkinje neurons (Khaliq et al., 2003; Levin et al., 2006).

Although resurgent gating appears to be necessary, it is not sufficient to enable fast spiking. GPe neurons, like other fastspiking neurons, also express Kv3 channels that keep spikes brief (minimizing fast inactivation) and that deactivate rapidly, allowing the membrane potential to rise back to spike threshold quickly (Rudy and McBain, 2001; Baranauskas et al., 2003; Akemann and Knopfel, 2006). Both striatal cholinergic interneurons and nigral dopaminergic neurons lack strong expression of Kv3 channels and have broad spikes; as a consequence, these cells are not capable of fast spiking, despite their expression of $\mathrm{Na}^{+}$channels with prominent resurgent gating (data not shown).

\section{Implications for DBS in PD}

In $\mathrm{PD}$ patients and in models of $\mathrm{PD}$, rhythmic, high-frequency burst spiking emerges in GPe and STN neurons (Wichmann and DeLong, 1999; Magill et al., 2000; Raz et al., 2001). In late-stage PD patients, HFSDBS of this GPe/STN network dramatically alleviates many motor symptoms (Vitek et al., 2004; Hamani et al., 2006). How HFS-DBS works is controversial. The similarity of the behavioral outcome of STN HFS-DBS and STN lesioning suggests that it functionally inactivates neurons by producing a depolarization block (Benabid et al., 2002). Direct tests of the depolarization block hypothesis have been difficult. Indirect tests suggest that axons leaving the STN are not blocked (Windels et al., 2005). Our results suggest that GPe neurons are capable of sustained spiking activity well in excess of the rates (90-120

$\mathrm{Hz}$ ) that are therapeutically effective in $\mathrm{PD}$ patients. At room temperature, GPe neurons were capable of spiking at over $150 \mathrm{~Hz}$ in response to intracellular current injection. Using a DBS-like intracellular stimulation protocol, GPe neurons did not simply stop spiking when driven at high frequencies for sustained periods but rather settled into a preferred spiking rate; at body temperature $\left(\sim 15^{\circ} \mathrm{C}\right.$ warmer; $Q_{10}$ of $\left.2-3\right)$ (Hille, 2001$)$, GPe neurons should be capable of sustained spiking at frequencies in excess of 100-150 Hz. Nav1.6 $\mathrm{Na}^{+}$channels were critical to this ability because GPe neurons lacking them rapidly descended into complete depolarization block at higher stimulation frequencies. The profound dependence of fast spiking in GPe neurons on Nav1.6 channels and resurgent current suggests that reducing expression of these channels would curtail pathological rhythmic burst spiking without compromising normal functional discharge patterns.

\section{References}

Afshari FS, Ptak K, Khaliq ZM, Grieco TM, Slater NT, McCrimmon DR, Raman IM (2004) Resurgent Na currents in four classes of neurons of the cerebellum. J Neurophysiol 92:2831-2843.
B driven activity Nav1.6 present

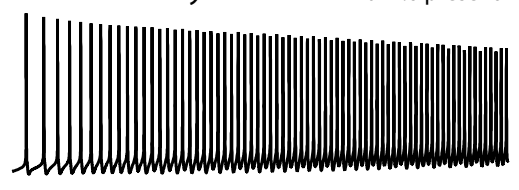

Nav1.6 removed

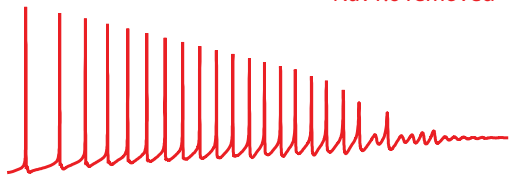

Nav1.6 replaced

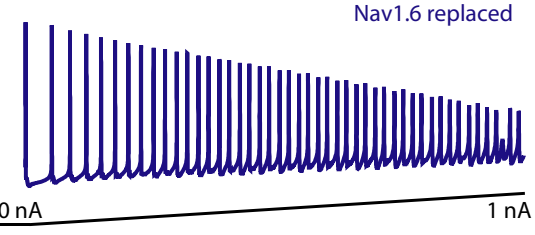

D

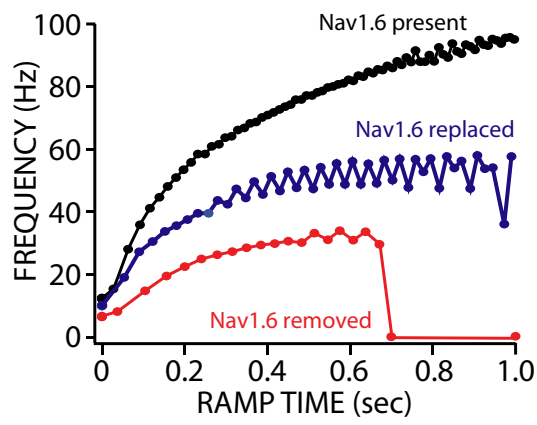

Figure 10. Simulations suggest that Nav1.6 channels are critical to fast spiking but not pacemaking. $\boldsymbol{A}$, Autonomous activity in a the model wild-type neuron at $12 \mathrm{~Hz}$ when the complete complement of $\mathrm{Na}^{+}$ channels is present. Middle trace, Spiking of the model neuron is reduced to $5 \mathrm{~Hz}$ when model Nav1.6 channels are simply deleted he model. Bottom trace, Spiking of the model neuron is restored to near that of the wild-type model when $\mathrm{Na}^{+}$channe density is maintained by replacing model Nav1.6 channels with model Nav1.1 channels. $\boldsymbol{B}$, The response of the same three models 1.6 channels improved the performance of the model, but the peak discharge rate was still well below that of the model with modNav1.6 channels (bottom). C, Cumulative frequency probability plot summarizing the firing capacity of the three models in response to ramp current injection. $\boldsymbol{D}$, The instantaneous discharge rate is plotted as a function of time during the ramp current injection for the three models.

Agrawal N, Hamam BN, Magistretti J, Alonso A, Ragsdale DS (2001) Persistent sodium channel activity mediates subthreshold membrane potential oscillations and low-threshold spikes in rat entorhinal cortex layer $\mathrm{V}$ neurons. Neuroscience 102:53-64.

Akemann W, Knopfel T (2006) Interaction of Kv3 potassium channels and resurgent sodium current influences the rate of spontaneous firing of Purkinje neurons. J Neurosci 26:4602-4612.

Albin RL, Young AB, Penney JB (1989) The functional anatomy of basal ganglia disorders. Trends Neurosci 12:366-375.

Baranauskas G, Martina M (2006) Sodium currents activate without a Hodgkin-and-Huxley-type delay in central mammalian neurons. J Neurosci 26:671-684.

Baranauskas G, Tkatch T, Surmeier DJ (1999) Delayed rectifier currents in rat globus pallidus neurons are attributable to Kv2.1 and $\mathrm{Kv} 3.1 / 3.2 \mathrm{~K}^{+}$ channels. J Neurosci 19:6394-6404.

Baranauskas G, Tkatch T, Nagata K, Yeh JZ, Surmeier DJ (2003) Kv3.4 subunits enhance the repolarizing efficiency of Kv3.1 channels in fast-spiking neurons. Nat Neurosci 6:258-266.

Benabid AL, Benazzouz A, Hoffmann D, Limousin P, Krack P, Pollak P (1998) Long-term electrical inhibition of deep brain targets in movement disorders. Mov Disord 13 [Suppl 3]:119-125.

Benabid AL, Benazzous A, Pollak P (2002) Mechanisms of deep brain stimulation. Mov Disord 17 [Suppl 3]:S73-S74. 
Bergman H, Wichmann T, DeLong MR (1990) Reversal of experimental parkinsonism by lesions of the subthalamic nucleus. Science 249:1436-1438.

Bevan MD, Wilson CJ (1999) Mechanisms underlying spontaneous oscillation and rhythmic firing in rat subthalamic neurons. J Neurosci 19:7617-7628.

Bevan MD, Magill PJ, Terman D, Bolam JP, Wilson CJ (2002) Move to the rhythm: oscillations in the subthalamic nucleus-external globus pallidus network. Trends Neurosci 25:525-531.

Boiko T, Rasband MN, Levinson SR, Caldwell JH, Mandel G, Trimmer JS, Matthews G (2001) Compact myelin dictates the differential targeting of two sodium channel isoforms in the same axon. Neuron 30:91-104.

Boiko T, Van Wart A, Caldwell JH, Levinson SR, Trimmer JS, Matthews G (2003) Functional specialization of the axon initial segment by isoformspecific sodium channel targeting. J Neurosci 23:2306-2313.

Caldwell JH, Schaller KL, Lasher RS, Peles E, Levinson SR (2000) Sodium channel $\mathrm{Na}_{\mathrm{v}} 1.6$ is localized at nodes of Ranvier, dendrites, and synapses. Proc Natl Acad Sci USA 97:5616-5620.

Carr DB, Day M, Cantrell AR, Held J, Scheuer T, Catterall WA, Surmeier DJ (2003) Transmitter modulation of slow, activity-dependent alterations in sodium channel availability endows neurons with a novel form of cellular plasticity. Neuron 39:793-806.

Chan CS, Shigemoto R, Mercer JN, Surmeier DJ (2004) HCN2 and HCN1 channels govern the regularity of autonomous pacemaking and synaptic resetting in globus pallidus neurons. J Neurosci 24:9921-9932.

Chen Y, Yu FH, Surmeier DJ, Scheuer T, Catterall WA (2006) Neuromodulation of $\mathrm{Na}^{+}$channel slow inactivation via cAMP-dependent protein kinase and protein kinase C. Neuron 49:409-420.

Clark BA, Monsivais P, Branco T, London M, Hausser M (2005) The site of action potential initiation in cerebellar Purkinje neurons. Nat Neurosci 8:137-139.

Colbert CM, Johnston D (1996) Axonal action-potential initiation and $\mathrm{Na}^{+}$channel densities in the soma and axon initial segment of subicular pyramidal neurons. J Neurosci 16:6676-6686.

Colbert CM, Pan E (2002) Ion channel properties underlying axonal action potential initiation in pyramidal neurons. Nat Neurosci 5:533-538.

Cummins TR, Dib-Hajj SD, Herzog RI, Waxman SG (2005) Nav1.6 channels generate resurgent sodium currents in spinal sensory neurons. FEBS Lett 579:2166-2170.

D’Angelo E, Nieus T, Maffei A, Armano S, Rossi P, Taglietti V, Fontana A, Naldi G (2001) Theta-frequency bursting and resonance in cerebellar granule cells: experimental evidence and modeling of a slow $\mathrm{K}^{+}$dependent mechanism. J Neurosci 21:759-770.

Day M, Carr DB, Ulrich S, Ilijic E, Tkatch T, Surmeier DJ (2005) Dendritic excitability of mouse frontal cortex pyramidal neurons is shaped by the interaction among HCN, Kir2, and Kleak channels. J Neurosci 25:8776-8787.

Do MT, Bean BP (2003) Subthreshold sodium currents and pacemaking of subthalamic neurons: modulation by slow inactivation. Neuron 39:109-120.

Do MT, Bean BP (2004) Sodium currents in subthalamic nucleus neurons from Nav1.6-null mice. J Neurophysiol 92:726-733.

Ellerkmann RK, Riazanski V, Elger CE, Urban BW, Beck H (2001) Slow recovery from inactivation regulates the availability of voltage-dependent $\mathrm{Na}^{+}$channels in hippocampal granule cells, hilar neurons and basket cells. J Physiol (Lond) 532:385-397.

Enomoto A, Han JM, Hsiao CF, Wu N, Chandler SH (2006) Participation of sodium currents in burst generation and control of membrane excitability in mesencephalic trigeminal neurons. J Neurosci 26:3412-3422.

Filion M, Tremblay L (1991) Abnormal spontaneous activity of globus pallidus neurons in monkeys with MPTP-induced parkinsonism. Brain Res 547:142-151.

Fohlmeister JF, Miller RF (1997) Mechanisms by which cell geometry controls repetitive impulse firing in retinal ganglion cells. J Neurophysiol 78:1948-1964.

Goldin AL (2001) Resurgence of sodium channel research. Annu Rev Physiol 63:871-894.

Grieco TM, Malhotra JD, Chen C, Isom LL, Raman IM (2005) Openchannel block by the cytoplasmic tail of sodium channel beta4 as a mechanism for resurgent sodium current. Neuron 45:233-244.

Hamani C, Neimat J, Lozano AM (2006) Deep brain stimulation for the treatment of Parkinson's disease. J Neural Transm Suppl 393-399.
Hille B (2001) Ion channels of excitable membranes, Ed 3. Sunderland, MA: Sinauer.

Hines ML, Carnevale NT (1997) The NEURON simulation environment. Neural Comput 9:1179-1209.

Hines ML, Carnevale NT (2001) NEURON: a tool for neuroscientists. The Neuroscientist 7:123-135.

Jung HY, Mickus T, Spruston N (1997) Prolonged sodium channel inactivation contributes to dendritic action potential attenuation in hippocampal pyramidal neurons. J Neurosci 17:6639-6646.

KhaliqZM, Gouwens NW, Raman IM (2003) The contribution of resurgent sodium current to high-frequency firing in Purkinje neurons: an experimental and modeling study. J Neurosci 23:4899-4912.

Kita H, Kitai ST (1991) Intracellular study of rat globus pallidus neurons: membrane properties and responses to neostriatal, subthalamic and nigral stimulation. Brain Res 564:296-305.

Kohrman DC, Plummer NW, Schuster T, Jones JM, Jang W, Burgess DL, Galt J, Spear BT, Meisler MH (1995) Insertional mutation of the motor endplate disease (med) locus on mouse chromosome 15. Genomics 26:171-177.

Krzemien DM, Schaller KL, Levinson SR, Caldwell JH (2000) Immunolocalization of sodium channel isoform $\mathrm{NaCh} 6$ in the nervous system. J Comp Neurol 420:70-83.

Kuo CC, Bean BP (1994) $\mathrm{Na}^{+}$channels must deactivate to recover from inactivation. Neuron 12:819-829.

Levin SI, Khaliq ZM, Aman TK, Grieco TM, Kearney JA, Raman IM, Meisler $\mathrm{MH}$ (2006) Impaired motor function in mice with cell-specific knockout of sodium channel Scn8a (NaV1.6) in cerebellar Purkinje neurons and granule cells. J Neurophysiol 96:785-793.

Lozano AM, Dostrovsky J, Chen R, Ashby P (2002) Deep brain stimulation for Parkinson's disease: disrupting the disruption. Lancet Neurol 1:225-231.

Magill PJ, Bolam JP, Bevan MD (2000) Relationship of activity in the subthalamic nucleus-globus pallidus network to cortical electroencephalogram. J Neurosci 20:820-833.

Magistretti J, Castelli L, Forti L, D’Angelo E (2006) Kinetic and functional analysis of transient, persistent and resurgent sodium currents in rat cerebellar granule cells in situ: an electrophysiological and modelling study. J Physiol (Lond) 573:83-106.

Martina M, Jonas P (1997) Functional differences in $\mathrm{Na}^{+}$channel gating between fast-spiking interneurones and principal neurones of rat hippocampus. J Physiol (Lond) 505:593-603.

Maurice N, Mercer J, Chan CS, Hernandez-Lopez S, Held J, Tkatch T, Surmeier DJ (2004) $\mathrm{D}_{2}$ dopamine receptor-mediated modulation of voltage-dependent $\mathrm{Na}^{+}$channels reduces autonomous activity in striatal cholinergic interneurons. J Neurosci 24:10289-10301.

McCormick DA, Shu Y, Yu Y (2007) Neurophysiology: Hodgkin and Huxley model—still standing? Nature 445:E1-E2; discussion E2-E3.

Meeks JP, Mennerick S (2007) Action potential initiation and propagation in CA3 pyramidal axons. J Neurophysiol 97:3460-3472.

Mickus T, Jung H, Spruston N (1999) Properties of slow, cumulative sodium channel inactivation in rat hippocampal CA1 pyramidal neurons. Biophys J 76:846-860.

Migliore M, Cook EP, Jaffe DB, Turner DA, Johnston D (1995) Computer simulations of morphologically reconstructed CA3 hippocampal neurons. J Neurophysiol 73:1157-1168.

Nambu A, Llinas R (1994) Electrophysiology of globus pallidus neurons in vitro. J Neurophysiol 72:1127-1139.

Narahashi T, Deguchi T, Urakawa N, Ohkubo Y (1960) Stabilization and rectification of muscle fiber membrane by tetrodotoxin. Am J Physiol 198:934-938.

Palmer LM, Stuart GJ (2006) Site of action potential initiation in layer 5 pyramidal neurons. J Neurosci 26:1854-1863.

Pennartz CM, Bierlaagh MA, Geurtsen AM (1997) Cellular mechanisms underlying spontaneous firing in rat suprachiasmatic nucleus: involvement of a slowly inactivating component of sodium current. J Neurophysiol 78:1811-1825.

Raman IM, Bean BP (1997) Resurgent sodium current and action potential formation in dissociated cerebellar Purkinje neurons. J Neurosci 17:4517-4526.

Raman IM, Bean BP (1999) Ionic currents underlying spontaneous action potentials in isolated cerebellar Purkinje neurons. J Neurosci 19:1663-1674. 
Raman IM, Bean BP (2001) Inactivation and recovery of sodium currents in cerebellar Purkinje neurons: evidence for two mechanisms. Biophys J 80:729-737.

Raman IM, Gustafson AE, Padgett D (2000) Ionic currents and spontaneous firing in neurons isolated from the cerebellar nuclei. J Neurosci 20:9004-9016.

Raz A, Vaadia E, Bergman H (2000) Firing patterns and correlations of spontaneous discharge of pallidal neurons in the normal and the tremulous 1-methyl-4-phenyl-1,2,3,6-tetrahydropyridine vervet model of parkinsonism. J Neurosci 20:8559-8571.

Raz A, Frechter-Mazar V, Feingold A, Abeles M, Vaadia E, Bergman H (2001) Activity of pallidal and striatal tonically active neurons is correlated in MPTP-treated monkeys but not in normal monkeys. J Neurosci 21:RC128(1-5)

Rudy B, McBain CJ (2001) Kv3 channels: voltage-gated $\mathrm{K}^{+}$channels designed for high-frequency repetitive firing. Trends Neurosci 24:517-526.

Shammah-Lagnado SJ, Alheid GF, Heimer L (1996) Efferent connections of the caudal part of the globus pallidus in the rat. J Comp Neurol 376:489-507.

Shen W, Hamilton SE, Nathanson NM, Surmeier DJ (2005) Cholinergic suppression of KCNQ channel currents enhances excitability of striatal medium spiny neurons. J Neurosci 25:7449-7458.

Song WJ, Tkatch T, Baranauskas G, Ichinohe N, Kitai ST, Surmeier DJ (1998) Somatodendritic depolarization-activated potassium currents in rat neostriatal cholinergic interneurons are predominantly of the A type and attributable to coexpression of Kv4.2 and Kv4.1 subunits. J Neurosci 18:3124-3137.

Stuart G, Schiller J, Sakmann B (1997) Action potential initiation and propagation in rat neocortical pyramidal neurons. J Physiol (Lond) 505:617-632.

Surmeier DJ, Mercer JN, Chan CS (2005) Autonomous pacemakers in the basal ganglia: who needs excitatory synapses anyway? Curr Opin Neurobiol 15:312-318.
Taddese A, Bean BP (2002) Subthreshold sodium current from rapidly inactivating sodium channels drives spontaneous firing of tuberomammillary neurons. Neuron 33:587-600.

Tkatch T, Baranauskas G, Surmeier DJ (1998) Basal forebrain neurons adjacent to the globus pallidus co-express GABAergic and cholinergic marker mRNAs. NeuroReport 9:1935-1939.

Tkatch T, Baranauskas G, Surmeier DJ (2000) Kv4.2 mRNA abundance and A-type $\mathrm{K}^{+}$current amplitude are linearly related in basal ganglia and basal forebrain neurons. J Neurosci 20:579-588.

Tzoumaka E, Tischler AC, Sangameswaran L, Eglen RM, Hunter JC, Novakovic SD (2000) Differential distribution of the tetrodotoxin-sensitive rPN4/NaCh6/Scn8a sodium channel in the nervous system. J Neurosci Res 60:37-44.

Van Wart A, Matthews G (2006) Impaired firing and cell-specific compensation in neurons lacking navl.6 sodium channels. J Neurosci 26:7172-7180.

Vitek JL, Hashimoto T, Peoples J, DeLong MR, Bakay RA (2004) Acute stimulation in the external segment of the globus pallidus improves parkinsonian motor signs. Mov Disord 19:907-915.

Wang J, Chen S, Nolan MF, Siegelbaum SA (2002) Activity-dependent regulation of HCN pacemaker channels by cyclic AMP: signaling through dynamic allosteric coupling. Neuron 36:451-461.

Wichmann T, DeLong MR (1999) Oscillations in the basal ganglia. Nature 400:621-622.

Windels F, Carcenac C, Poupard A, Savasta M (2005) Pallidal origin of GABA release within the substantia nigra pars reticulata during highfrequency stimulation of the subthalamic nucleus. J Neurosci 25:5079-5086.

Wittmack EK, Rush AM, Craner MJ, Goldfarb M, Waxman SG, Dib-Hajj SD (2004) Fibroblast growth factor homologous factor 2B: association with Nav1.6 and selective colocalization at nodes of Ranvier of dorsal root axons. J Neurosci 24:6765-6775. 